\title{
A New Simple Method for the Strength of High-Strength Steel Thin-Walled Box Columns Subjected to Axial Force and Biaxial End Moments
}

\author{
Hong-Xia Shen (i) \\ School of Civil Engineering, Xi'an University of Architecture and Technology, Xi' an, Shaanxi 710055, China \\ Correspondence should be addressed to Hong-Xia Shen; shenhongxia888@163.com
}

Received 9 April 2019; Accepted 1 July 2019; Published 18 July 2019

Academic Editor: Eric Lui

Copyright (c) 2019 Hong-Xia Shen. This is an open access article distributed under the Creative Commons Attribution License, which permits unrestricted use, distribution, and reproduction in any medium, provided the original work is properly cited.

\begin{abstract}
The strength of Q460 steel welded thin-walled box columns under biaxial bending is investigated by an FE model. The numerical results, together with available experimental data, are compared with the American Specification ANSI/AISC 360-10. It shows that ANSI/AISC 360-10 provides a good estimate over a wide range of column slenderness ratios; but it severely underestimates the strengths of beam-columns with large slenderness ratios and slightly underestimates those of beam-columns made from HSS with $f_{y}=741 \mathrm{MPa}$, and the calculation is more complicated because of using an effective width concept. Therefore, a simple and effective calculation method is proposed. Also, a comparison is made between the proposed formulas and the available experimental results. It shows that the proposed formulas can precisely evaluate the local-overall interactive buckling strength of HSS beamcolumns and, in most cases, are also suitable for beam-columns fabricated from mild steels. The proposed formulas are simple and, meanwhile, achieve the same level of accuracy as ANSI/AISC 360-10.
\end{abstract}

\section{Introduction}

Structural steel with a nominal yield stress (denoted by $f_{y}$ ) greater than or equal to $420 \mathrm{MPa}$ is often defined as highstrength steel (HSS). HSSs, such as Q460 and Q690, the nominal yield stress of which is $460 \mathrm{MPa}$ and $690 \mathrm{MPa}$, respectively, have been successfully applied in large-span structures, high-rise buildings, and transmission towers in China owing to having high plasticity, good toughness, and excellent weldability. Economical design of HSS structures leads to thin-walled members. These thinwalled members will, very likely, fail in a mode of interaction between local plate buckling and overall member buckling, also called local-overall interactive buckling, in which local buckling of plate elements occurs prior to overall buckling of members and the local buckling weakens the overall stiffness and reduces the overall buckling strength.

A large amount of research work has been done on the local-overall interaction buckling strength of welded I- and box-section columns [1-14], and beam-columns $[2,6,11$, $12,15-23]$. Nonetheless, at present, there are a few research studies about HSS beam-columns [11, 12, 20-23]. In the early 1980s, an experimental study was performed by Usami and Fukumoto $[11,12]$ on the local-overall interaction buckling strength of HSS welded box columns, and an empirical formula for the buckling strength was suggested. A total of 23 specimens with $f_{y}=460 \mathrm{MPa}$ and 27 specimens with $f_{y}=690 \mathrm{MPa}$ were tested to failure under concentric load and uniaxial eccentric load; material properties, residual stresses, and column initial deflections were also measured. The column slenderness ratios ranged from 30 to 65 and the plate width-to-thickness ratios from 22 to 58 . Until recent years, a series of numerical simulations of inplane and out-of-plane ultimate carrying capacities of Q460 steel welded I- and box-section columns loaded with an eccentricity in a plane of symmetry were conducted by Shen and Yang [20], Shen and Liu [21], Shen [22], and Shen and Zhao [23], respectively. The beam-columns were selected to cover a wide range of plate width-to-thickness ratios ranging 
from 40 to 70 and a wide range of member slenderness ratios from 20 to 120 . The effects of plate width-to-thickness ratio, column slenderness ratio, and eccentricity on the ultimate carrying capacities were investigated, and the calculation formulas for the ultimate strengths were proposed. However, all these studies focused on the HSS beam-columns under uniaxial bending, and more attention should be paid to those under biaxial bending.

In addition, no strength formulas are provided specially for HSS welded beam-columns in some existing standards GB 50017-2017 [24], ANSI/AISC 360-10 [25], EN 1993-1-1 [26], and EN 1993-1-5 [27]. These standards are all based on the research results of mild steels and are also used for HSSs, but it is unknown whether they are applicable for HSS members. Furthermore, when the strength of thin-walled box beam-columns under biaxial bending is calculated in accordance with the above standards, a cumbersome calculation has to be made because of the effective width method, which is used in these standards. Hence, a simple method needs to be provided.

In this study, the local-overall interaction buckling behavior of Q460 steel welded thin-walled box beam-columns under biaxial bending is analyzed by the commercial software ANSYS $8.0[28,29]$. The numerical results, as well as available experimental results of different steel grades, are compared with ANSI/AISC 360-10 to check whether ANSI/ AISC 360-10 is suitable for such types of beam-columns. Simple formulas are presented for predicting the localoverall interactive buckling strength of Q460 steel beamcolumns subjected to axial compression and biaxial bending moments. The proposed formulas are verified by comparing them with the available experimental results.

\section{Finite Element Analysis}

2.1. An FE Model and Its Verification. A pin-ended beamcolumn, as shown in Figure 1, with a welded thin-walled box cross section, fabricated from Q460, subjected to combined axial compression force, $P$, and biaxial bending moments, $M_{x}$ and $M_{y}$, is investigated in this paper. Here, the bending moments around the $x$ - and $y$-axes, $M_{x}$ and $M_{y}$, are taken as $M_{x}=P e_{y}$ and $M_{y}=P e_{x}$, where $e_{x}$ and $e_{y}$ are the eccentricities in the $x$ and $y$ directions, respectively. Also given in Figure 1(b) are the dimensions of the welded box section, in which $b$ and $h$ are the widths of plate elements and $t$ is the thickness of the plate elements.

A geometrical and material nonlinear FE model was established by Shen $[9,22]$ for HSS box columns loaded with axial compression and uniaxial eccentric compression, respectively, by using the ANSYS program. In this study, the FE model is modified for HSS box columns loaded with biaxial eccentric compression.

As described by Shen $[9,22]$, the effects of initial geometrical imperfections and residual stresses are taken into account. The initial geometrical imperfections include both overall member imperfections and local plate imperfections. The member imperfections are assumed to bend in a half sine wave about the major and minor axes, respectively, as follows:

$$
\begin{aligned}
& v_{0}=\frac{l}{1000} \sin \frac{\pi z}{l}, \\
& \mu_{0}=\frac{l}{1000} \sin \frac{\pi z}{l},
\end{aligned}
$$

where $l$ is the length of the member.

In equations ( $1 \mathrm{a})$ and ( $1 \mathrm{~b})$, the maximum value of out-ofstraightness of a member is taken equal to $l / 1000$ as specified by GB 50017-2003 [30] and ANSI/AISC 360-10 [25].

The plate imperfections are assumed as

$$
\begin{aligned}
& \omega=\omega_{1} \sin \frac{m \pi z}{l} \cos \frac{\pi x}{b} \quad\left(y= \pm\left(\frac{h}{2}+\frac{t}{2}\right)\right), \\
& \omega=\omega_{2} \sin \frac{m \pi z}{l} \cos \frac{\pi y}{h} \quad\left(x= \pm\left(\frac{b}{2}+\frac{t}{2}\right)\right),
\end{aligned}
$$

where $\omega_{1}=b / 1000, \omega_{2}=h / 1000$, and $m$ is the buckling halfwave number along the longitudinal axis of the member.

The magnitudes of plate imperfections were taken as $b / 100$ and $b / 1000$ ( $b$ is the plate width of a square box section) [8], and it showed that the magnitude of plate imperfections had a significant effect on the compressive strength of welded box columns. No uniform value was specified for the maximum of plate imperfections, and it was taken as 0.01 [4] and $b / 1000$ [3], but it was demonstrated that the value of $b / 1000$ seemed to be reasonable [3] when residual stresses were taken into consideration. Hence, for a square box section, $\omega_{1}=\omega_{2}=b / 1000$. But for a rectangular one, according to the deformation compatibility condition, the angle between the two adjacent plates remained unchanged before and after the plate buckling, so $\omega_{1}=b / 1000$ and $\omega_{2}=h / 1000$ herein.

Residual stress measurements of welded square and rectangular box sections were made by Usami and Fukumoto [11] and Pavlovčič et al. [6], respectively. According to their measurement results, a simplified pattern of residual stress distribution, as shown in Figure 2, is adopted, where tensile residual stresses are positive values and compressive stresses are negative values. An SM58 steel plate was used [11]; its nominal yield strength was $460 \mathrm{MPa}$, and its measured yield strength was $568 \mathrm{MPa}$. The maximum value of tensile stresses was about $80 \%$ of the measured yield strength, i.e., $0.8 \times 568=454 \mathrm{MPa}$, which is very close to the nominal yield strength of $460 \mathrm{MPa}$. The value of compressive residual stresses decreased along with the increase of the width-to-thickness ratio of the plate $[6,11]$. The distribution width of tensile residual stresses was about $3 t$ [9]. As a consequence, the maximum value of tensile residual stresses $\sigma_{\mathrm{rt}}$ is taken as the nominal yield stress of steel and those of compressive residual stresses $\sigma_{\text {rcf }}$ and $\sigma_{\text {rcw }}$, along the flange and web, respectively, may be obtained according to equilibrium conditions.

The Shell181 element is employed to take account of plate imperfections. Shell181 is suitable for analyzing thin to moderately thick shell structures. It is a 4-node element with six degrees of freedom at each node: translations in the $x, y$, and $z$ directions and rotations about the $x$-, $y$-, and $z$-axes. It is well suited for linear, large-rotation, and/or large-strain nonlinear applications. Also, the effects of plasticity of steel, 


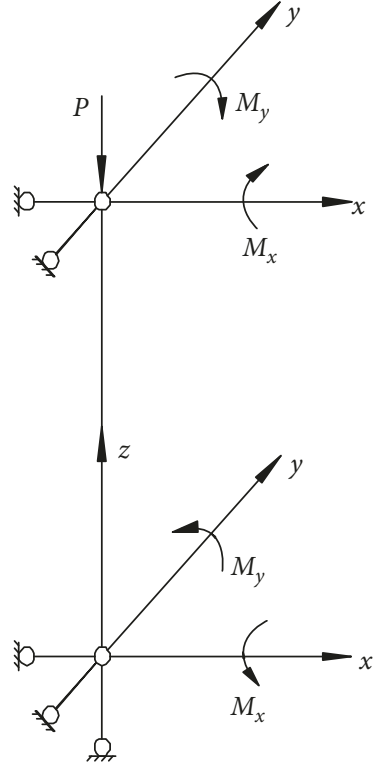

(a)

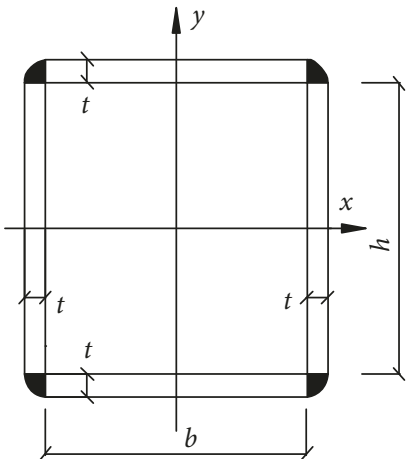

(b)

Figure 1: A beam-column subjected to biaxial bending: (a) a force diagram; (b) cross section and its dimensions.
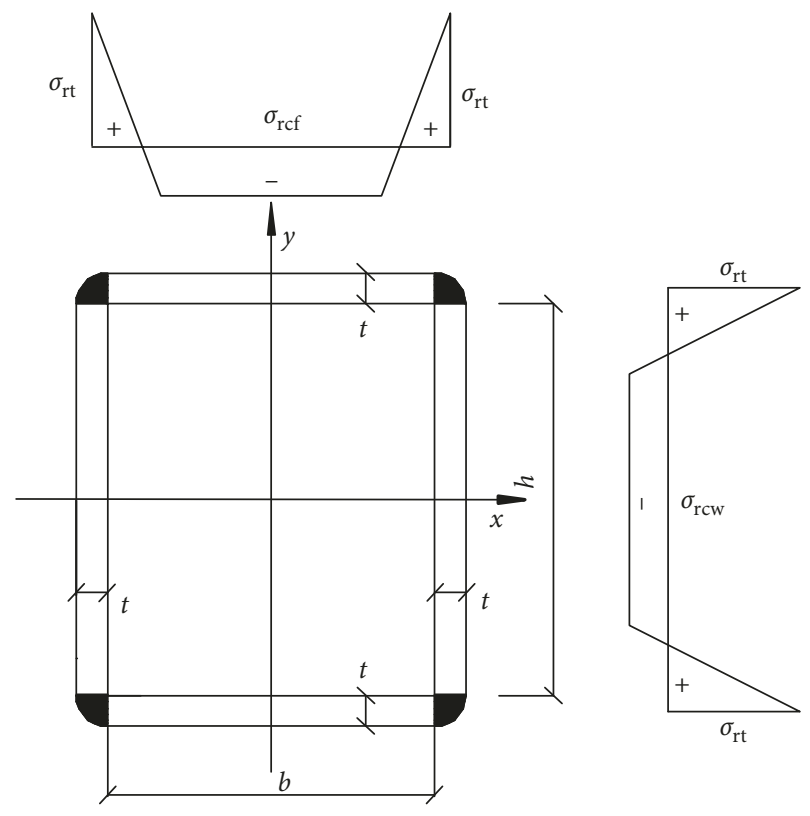

FIgURE 2: Residual stress distribution pattern.

member imperfections, and residual stresses can be considered by using Shell181. As a result, the Shell181 element satisfies the requirements of this study.

The experiment results [31] showed that stress-strain curves for Q460 steel, as shown in Figure 3, were similar to those for mild steel and also had a yield plateau. The material models with and without strain hardening had almost no influence on the compressive strength of welded box columns [8]. The similar finding was also noted by Pircher et al. [7] in the simulation of the buckling of thin-walled steel box tubes. So, an ideal elastic-plastic material model is assumed to represent the stress-strain relationship for Q460 steel. The

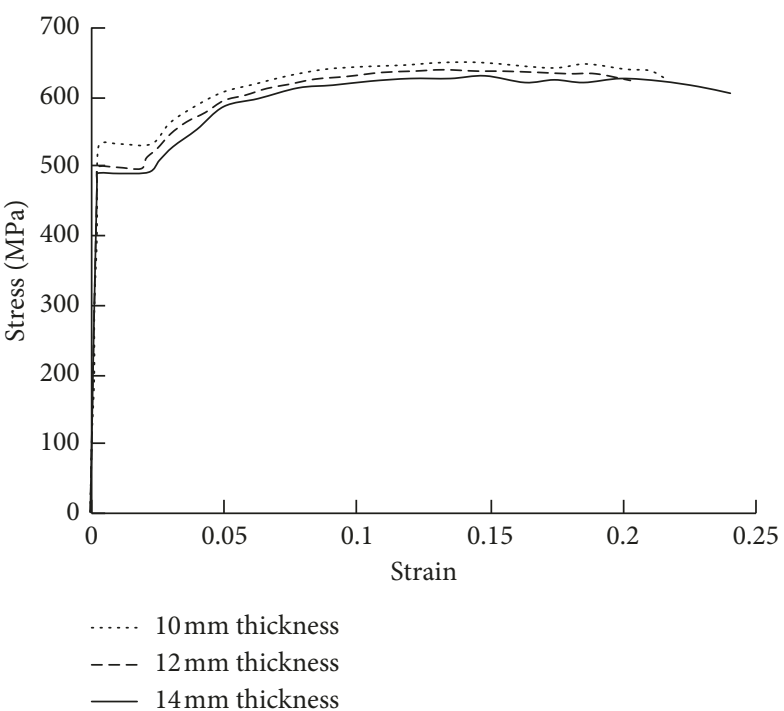

FIgURE 3: Stress-strain curves for Q460 steel.

nominal material properties: yield stress $f_{y}=460 \mathrm{~N} / \mathrm{mm}^{2}$, Young's modulus $E=206000 \mathrm{~N} / \mathrm{mm}^{2}$, Poisson's ratio $v=0.3$, and tangent modulus $E_{\mathrm{t}}=0$, are used.

The effect of geometrical imperfections is taken into account by direct modeling according to the following steps: Firstly, the number of nodes required in the FE model and the order in which the nodes should be generated are determined. Secondly, all nodes are generated according to the $x, y$, and $z$ coordinates considering geometrical imperfections. Thirdly, the element attributes, including the element type, material model, and real constant, have been set, and shell elements are automatically generated within each area defined by four nodes. For any plate element in a box column, element sizes are $b / 8$ or $h / 8$ along its width and $h / 4$ 
along its length, and thus, a finite element grid is $b / 8 \times h / 4$ or $h / 8 \times h / 4$. In this paper, the minimum grid is approximately $20 \mathrm{~mm} \times 40 \mathrm{~mm}$ and the maximum one $50 \mathrm{~mm} \times 100 \mathrm{~mm}$, which satisfies the accuracy requirement of the numerical simulation. Figure 4 shows the initial geometrical imperfections generated by direct modeling, in which the initial deflections are magnified 5,000 times only to be observed clearly.

Residual stresses are treated as initial stresses that are loads and must be applied at the integration points of Shell181 elements. For a Shell181 element, there are four integration points in its plane, together with 5 integration points in the thickness direction to take account of nonlinear bending properties, and thus, the total number of integration points is 20. In order to input initial stresses in the FE model, two steps must be performed: Firstly, an initial stress file needs to be written based on the integration point locations. Secondly, the initial stress file must be read by using the ISFILE command only at the first substep of the first load step, as specified in the ANSYS program. In this study, the same residual stress distributions are assumed, along the thickness direction, because of thin plate elements.

The loading and boundary conditions of the beamcolumns studied in this paper are different greatly from those of the beam-columns [22]. Figure 5 displays the loads and boundary conditions in the FE model. As shown in Figure 5, a $30 \mathrm{~mm}$ thick end plate is attached to both ends of a beam-column [32], and an eccentric load at every end of the member is equivalent to combined axial compressive force and biaxial bending moments. These forces, as well as the boundary conditions, are applied at the center points of both end plates [32]. At one end, $z=0$, besides the bending moments $M_{x}$ and $M_{y}$, the three translations $U_{x}, U_{y}$, and $U_{z}$ in the $x, y$, and $z$ directions and the rotation $\operatorname{Rot}_{z}$ about the $z$ axis are prevented, i.e., $U_{x}=U_{y}=U_{z}=\operatorname{Rot}_{z}=0$. At the other end, $z=l$, besides $P, M_{x}$, and $M_{y}$, the boundary conditions satisfy $U_{x}=U_{y}=\operatorname{Rot}_{z}=0$. In addition, both ends of the member are restrained against the rotation about the longitudinal axis by applying $U_{x}=U_{y}=0$ at the four corner points of the end plate.

The available experimental data are used to verify the FE model. 35 experimental specimens fabricated from two types of HSSs having $f_{y}=460 \mathrm{MPa}$ and $690 \mathrm{MPa}$, of which 21 were centrally loaded and 14 eccentrically loaded in a symmetry plane by Usami and Fukumoto [11, 12], were simulated by Shen [22], and the ratios of the numerical and experimental ultimate strength change from 0.901 to 1.084 with an average value of 1.012 and a standard deviation of $4.53 \%$. Here, the FE model [22] was modified for biaxial bending, but no published experimental information could be found on the beam-columns made from HSSs and subjected to biaxial bending. Hence, in this section, 28 experimental specimens tested by Richard Liew et al. [16], fabricated from mild steels with the nominal yield strength of $353 \mathrm{MPa}, 268 \mathrm{MPa}$, and $293 \mathrm{MPa}$, were simulated to verify the effectiveness of the modified FE model. Among these specimens, 10 were loaded with uniaxial eccentricity and labeled with a single letter X or $\mathrm{Y}$, as shown in Table 1 , and 18 were loaded with biaxial eccentricity and marked with two letters XY. The second field $S$ of the specimen number indicates a square box section, while $\mathrm{R}$ indicates a rectangular box section. The third field refers to the web depth-to-thickness ratio, and the last field denotes the column slenderness ratio about the minor axis. Also listed in Table 1 are the main parameters of the specimens, including the width-to-thickness ratio $b / t$; depth-to-thickness ratio $h / t$; maximum initial deflections $\delta_{0 x} / L$ and $\delta_{0 y} / L$ about $x$ - and $y$-axes, respectively; eccentricities $e_{x}$ and $e_{y}$ in $x$ and $y$ directions, respectively; and measured yield stress $f_{y}$. All these parameters, as well as the material's Young's modulus, Poisson's ratio, and residual stress patterns measured by Richard Liew et al. [16], are used.

A comparison between the experimental and numerical results is also presented in Table 1, where $P_{\exp }$ and $P_{\text {fem }}$ are the ultimate strengths obtained from the experimental result and numerical simulation, respectively. The ratios of the experimental and numerical ultimate strength, $P_{\exp } / P_{\text {fem }}$, vary within a range of 0.86 to 1.12 with an average value of 0.97 and a standard deviation of $6.8 \%$. It can be seen that the numerical results are in good agreement with the experimental ones, and the FE model established in this study can precisely predict the local-overall interactive buckling strength of welded box beam-columns under both uniaxial bending and biaxial bending.

\subsection{Buckling Behavior of Q460 Steel Welded Thin-Walled Box} Beam-Columns. By using the FE model mentioned above, a great amount of numerical simulation work with different parameters has been performed on the local-overall interactive buckling of Q460 steel thin-walled box columns under the biaxial eccentric loading condition. The parameters include the cross-sectional shape, plate width-tothickness ratio, column slenderness ratio, and applied eccentricities $e_{x}$ and $e_{y}$.

In the calculation, the cross sections include square and rectangular box sections and the depth-to-width ratio of the rectangular boxes is 1.25. The thickness of the plate elements, $t$, is taken as $4 \mathrm{~mm}$ and kept constant.

Plate width-to-thickness ratios, together with column slenderness ratios, are selected elaborately to ensure that the local-overall interaction buckling occurs. In accordance with the Chinese Code GB 50017-2003 [30], the limiting widthto-thickness ratio is $40 \sqrt{235 / f_{y}}=40 \times \sqrt{235 / 460}=28.6$ for compression elements of members subjected to axial compression and bending. This limiting value is $1.4 \sqrt{E / F_{y}}=$ $1.4 \times \sqrt{206000 / 460}=29.6$ in ANSI/AISC 360-10 [25]. Both of them are basically the same. When the width-to-thickness ratio is greater than the limiting value, the local-overall interaction buckling will occur. Therefore, the width-tothickness ratio, $b / t$, is taken as $40,50,60,70$, and 80 , respectively, whether a square or a rectangular box cross section. If it is a rectangular box, the corresponding depthto-thickness ratio, $h / t$, will be $50,62.5,75,87.5$, and 100 , respectively.

To obtain the predicated failure mode of local-overall interaction buckling, the beam-columns with medium slenderness ratios should be selected. Therefore, the member slenderness ratio about the major axis, $\lambda_{x}\left(\lambda_{x}=l / i_{x}\right.$, where $l$ is 


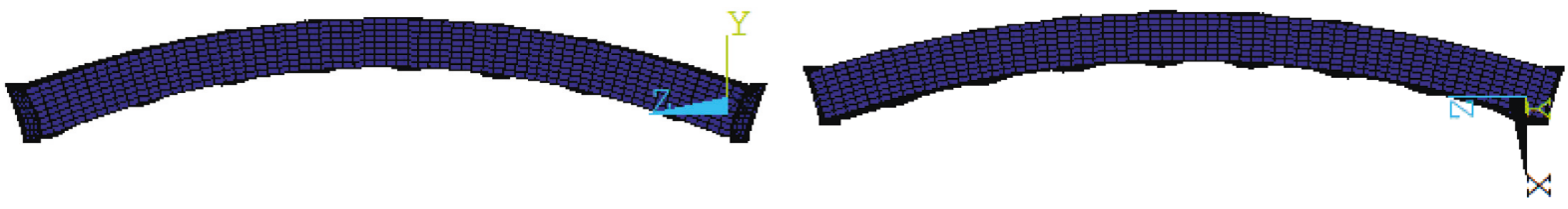

(a)

(b)

FIgURE 4: Initial geometrical imperfections: plate imperfections and member imperfections about the (a) $x$-axis and (b) $y$-axis.

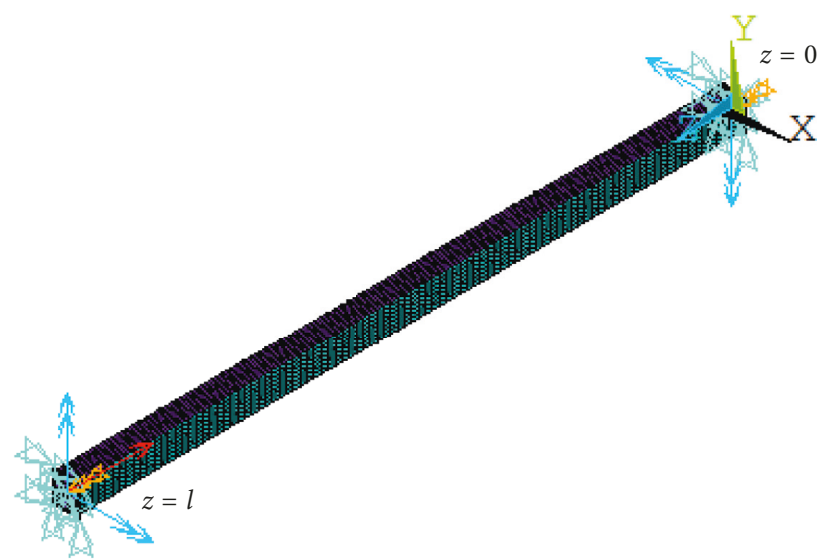

(a)

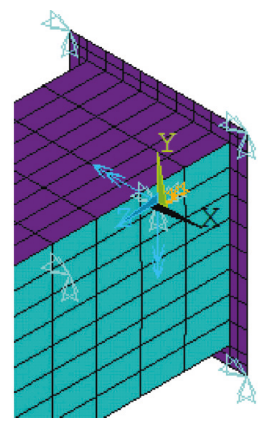

(b)

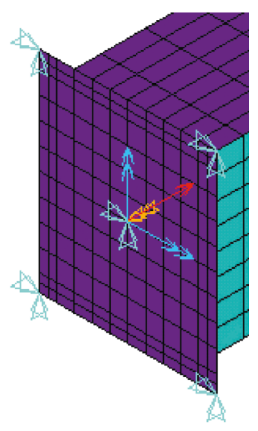

(c)

FiguRE 5: Loading and boundary conditions: (a) overall model; (b) loads and boundary conditions at $z=0$; (c) loads and boundary conditions at $z=l$.

TABLE 1: Comparison between the experimental and numerical results [16].

\begin{tabular}{|c|c|c|c|c|c|c|c|c|c|c|c|}
\hline No. & Specimen & $b / t$ & $h / t$ & $\delta_{0 x} / L\left(\times 10^{-4}\right)$ & $\delta_{0 y} / L\left(\times 10^{-4}\right)$ & $e_{x}(\mathrm{~mm})$ & $e_{y}(\mathrm{~mm})$ & $f_{y}\left(\mathrm{~N} / \mathrm{mm}^{2}\right)$ & $P_{\exp }(\mathrm{kN})$ & $P_{\text {fem }}(\mathrm{kN})$ & $P_{\text {exp }} / P_{\text {fem }}$ \\
\hline 1 & X-S-30-85 & 29.5 & 29.8 & - & 0.6 & 15 & 0 & 353 & 209.99 & 204.62 & 1.03 \\
\hline 2 & XY-S-30-85a & 29.5 & 29.8 & 1.75 & -3.67 & 5 & 10 & 353 & 224.62 & 207.84 & 1.08 \\
\hline 3 & XY-S-30-85b & 29.2 & 29.2 & 0.63 & 0.75 & 5 & 5 & 353 & 254.37 & 227.88 & 1.12 \\
\hline 4 & X-S-45-57 & 43.9 & 44.6 & - & 0.8 & 15 & 0 & 353 & 325.30 & 334.81 & 0.97 \\
\hline 5 & XY-S-45-57a & 44.2 & 44.2 & 3.77 & 2.14 & 5 & 15 & 353 & 312.24 & 330.87 & 0.94 \\
\hline 6 & XY-S-45-57b & 44.2 & 44.2 & -1.89 & -2.33 & 15 & 15 & 353 & 286.74 & 306.55 & 0.94 \\
\hline 7 & X-S-52-48 & 52.4 & 52.4 & - & 0.88 & 20 & 0 & 353 & 324.73 & 317.24 & 1.02 \\
\hline 8 & XY-S-52-48a & 52.4 & 52.4 & 1.89 & 2.51 & 15 & 10 & 353 & 338.72 & 314.20 & 1.08 \\
\hline 9 & XY-S-52-48b & 52.1 & 51.8 & 1.51 & 1.76 & 10 & 10 & 353 & 348.63 & 335.61 & 1.04 \\
\hline 10 & Y-S-64-64 & 64.2 & 64.2 & 3.00 & - & 0 & 10 & 268 & 114.39 & 117.42 & 0.97 \\
\hline 11 & XY-S-64-64a & 64.2 & 63.7 & 2.33 & 6.41 & 10 & 5 & 268 & 108.18 & 115.63 & 0.94 \\
\hline 12 & XY-S-64-64b & 64.8 & 64.2 & 4.53 & 5.03 & 15 & 15 & 268 & 83.25 & 88.30 & 0.94 \\
\hline 13 & X-S-75-55 & 75.9 & 75.9 & - & 2.77 & 15 & 0 & 268 & 118.11 & 124.63 & 0.95 \\
\hline 14 & XY-S-75-55a & 75.9 & 75.3 & 1.89 & 3.78 & 15 & 10 & 268 & 109.24 & 117.73 & 0.93 \\
\hline 15 & XY-S-75-55b & 75.5 & 75.3 & 0.6 & 1.89 & 15 & 15 & 268 & 102.63 & 113.60 & 0.90 \\
\hline 16 & Y-S-85-48 & 86 & 85.6 & -2.76 & - & 0 & 20 & 268 & 117.66 & 124.50 & 0.95 \\
\hline 17 & XY-S-85-48a & 85 & 86.1 & -4.66 & 4.66 & 20 & 10 & 268 & 115.30 & 121.50 & 0.95 \\
\hline 18 & XY-S-85-48b & 86 & 85.6 & -1.89 & -4.41 & 15 & 15 & 268 & 111.59 & 120.00 & 0.93 \\
\hline 19 & X-R-53-64 & 40.3 & 53.7 & - & -3.78 & 19 & 0 & 293 & 261.76 & 251.57 & 1.04 \\
\hline 20 & XY-R-53-64a & 39.6 & 54 & 3.78 & 4.28 & 20 & 10 & 293 & 260.37 & 237.00 & 1.10 \\
\hline 21 & XY-R-53-64b & 39.6 & 54 & -4.41 & 4.41 & 20 & 20 & 293 & 236.70 & 237.00 & 1.00 \\
\hline 22 & XY-R-53-64c & 39.9 & 53.7 & -5.54 & -3.15 & 10 & 20 & 293 & 268.97 & 264.00 & 1.02 \\
\hline 23 & Y-R-53-64 & 39.9 & 54 & -4.41 & -1.25 & 0 & 20 & 293 & 311.95 & 314.78 & 0.99 \\
\hline 24 & X-R-86-62 & 70 & 86.1 & - & -2.51 & 20 & 0 & 268 & 105.21 & 114.06 & 0.92 \\
\hline 25 & XY-R-86-62a & 70 & 86.1 & 3.96 & -4.66 & 20 & 10 & 268 & 97.14 & 110.85 & 0.88 \\
\hline 26 & XY-R-86-62b & 70 & 86.1 & -2.93 & 4.09 & 20 & 20 & 268 & 93.72 & 109.21 & 0.86 \\
\hline 27 & XY-R-86-62c & 70 & 86.1 & 2.52 & 3.78 & 10 & 20 & 268 & 102.72 & 115.50 & 0.89 \\
\hline 28 & Y-R-86-62 & 70 & 86.1 & -4.66 & 2.67 & 0 & 20 & 268 & 114.52 & 123.00 & 0.93 \\
\hline \multirow{2}{*}{\multicolumn{2}{|c|}{$\begin{array}{l}\text { Average } \\
\text { Standard deviation } \\
(\%)\end{array}$}} & & & & & & & & & & 0.97 \\
\hline & & & & & & & & & & & 6.8 \\
\hline
\end{tabular}


the effective length of a member and $i_{x}$ is the gyration radius about the major axis, i.e., $x$-axis), is taken equal to $40,60,80$, and 100 , respectively.

Eccentricities $e_{x}$ and $e_{y}$ are taken as two of $10 \mathrm{~mm}$, $15 \mathrm{~mm}, 20 \mathrm{~mm}, 25 \mathrm{~mm}, 30 \mathrm{~mm}, 35 \mathrm{~mm}, 40 \mathrm{~mm}$, and $50 \mathrm{~mm}$, respectively, satisfying $e_{x}=e_{y}$ or $e_{y}-e_{x}=5 \mathrm{~mm}$ in order to save materials.

The beam-columns are marked with numbers, such as S-40-40 $(10,10)$, in which the first $S$ indicates a square box section, the second is the width-to-thickness ratio, the third is the column slenderness ratio about the $x$-axis, and the figures in brackets are the eccentricities $e_{x}$ and $e_{y}$, respectively. If it is a rectangular box section, $\mathrm{S}$ is replaced by $\mathrm{R}$, and another figure following the second part is added representing the depth-to-thickness ratio.

2.2.1. Load-Displacement or Load-Rotation Curves. Figure 6 shows the flexural deformation of a beam-column, where $\mu_{\max }$ and $v_{\max }$ are the maximum deflections in the $x$ and $y$ directions, respectively, and the section $1-1$ is the cross section of the member at midlength. Points $A$ and $B$ are the midpoints of the upper flange and left web of the cross section 1-1, respectively. Owing to the interaction between local buckling and biaxial bending, the maximum deflections in the $x$ and $y$ directions of the points on the cross-section 1-1 are different from each other. In this study, $\mu_{\max }$ is taken as the deflection of the point $B$ and $v_{\max }$ as that of the point $A$.

There is a large difference in values of the displacement between a long and a short column, so their load-displacement and load-rotation curves are plotted separately. Figures 7 and 8 show the typical ones for the member S-40$40(40,40)$ that represents a short column and the ones for the member S-50-100 $(30,35)$ that represents a long column, respectively. In Figures 7 and 8, the curves of the axial compressive force, $P$, versus the axial compressive displacement, $\Delta$, the maximum deflection in the $x$ direction, $\mu_{\text {max }}$, the maximum deflection in the $y$ direction, $v_{\max }$, and the maximum rotation about the $z$-axis, $\theta_{\max }$, which is taken as the rotation of the point $A$ as above, are shown, respectively. It can be seen from Figures 7 and 8 that when reaching the ultimate strengths $(440.36 \mathrm{kN}$ and $338.45 \mathrm{kN})$, for the member S-40-40 (40, 40), $\Delta=7.21 \mathrm{~mm}$, $\mu_{\max }=12.24 \mathrm{~mm}, \quad v_{\max }=12.86 \mathrm{~mm}$, and $\theta_{\max }=0.005 \mathrm{rad}$, while for the member S-50-100 (30, 35), $\Delta=12.71 \mathrm{~mm}$, $\mu_{\max }=64.92 \mathrm{~mm}, v_{\max }=84.93 \mathrm{~mm}$, and $\theta_{\max }=-0.001 \mathrm{rad}$. From these values, a conclusion can be drawn that the bending deflections about the $x$ - and $y$-axes and axial compressive displacement are large and the rotation about the $z$-axis is very small for both the short and long boxsection beam-columns subjected to biaxial bending. Such a small twisting effect is due to the fact that a box section has large torsional rigidity.

2.2.2. Von Mises Stress Distribution of the Cross Section at Midlength. A biaxial bending beam-column of this type might be in the elastic region when it reaches the maximum strength. It can be determined by viewing von Mises stress distribution. A typical member R-50-62.5-60 with $b / t=50$, $h / t=62.5$, and $\lambda_{x}=60$ is selected to exhibit the von Mises stress distribution of the cross-section 1-1, as shown in Figure 6, where the maximum bending moments occur.

To make it easier to describe the von Mises stress distribution, the coordinate system, as shown in Figure 6, is defined again. The top-left corner point of the cross-section $1-1$ is taken as the coordinate origin, the $x$-axis is horizontal with values increasing from left to right, and the $y$-axis is vertical with values increasing from top to bottom. The von Mises stress distributions at the ultimate loads are plotted in Figure 9 under different eccentricities. In Figure 9, all eccentricities $e_{x}$ and $e_{y}$ are in $\mathrm{mm}$. A little difference in von Mises stress distributions exists in the bottom flange and right web under eight different eccentricities, but obvious difference is observed in the top flange and left web. The maximum von Mises stress of $452.77 \mathrm{MPa}$ occurs at the corner point between the top flange and the left web when $e_{x}=50 \mathrm{~mm}$ and $e_{y}=50 \mathrm{~mm}$. All these stresses are smaller than the steel yield stress of $460 \mathrm{MPa}$, and the beam-column is still in the elastic range and does not enter the elasticplastic range under any eccentricity condition.

\subsubsection{Interaction between Bending Moment and Axial Force.} It is very important for a beam-column subjected to biaxial bending to find the relationship equation between the axial load and end bending moments. The scatter diagrams between $P_{u} / P_{y}$ and $M_{u x} / M_{x y}$ (or $\left.M_{u y} / M_{y y}\right)$ of Q460 steel thinwalled box-section beam-columns with five different widthto-thickness ratios are essentially the same, so Figures 10 and 11 only show the ones for beam-columns with square box sections and $b / t=40,60$, and 80 and for those with rectangular box sections and $b / t=60$ and 80 , respectively, where $M_{u x}=P_{u} e_{y}, \quad M_{u y}=P_{u} e_{x}, \quad P_{y}=A f_{y}, \quad M_{x y}=W_{x} f_{y}, \quad$ and $M_{y y}=W_{y} f_{y}$ ( $A$ is the gross area and $W_{x}$ and $W_{y}$ are the gross section moduli about $x$ - and $y$-axes, respectively). In Figures 10 and 11, the scatter plots are the finite element results, and also, the straight lines that predict the changing trends of all the coordinate points are added. It is seen in Figures 10 and 11 that the straight lines can fit very well the overall trend of the scatter plots between $P_{u} / P_{y}$ and $M_{u x} / M_{x y}\left(\right.$ or $\left.M_{u y} / M_{y y}\right)$.

\section{Evaluation of the American National Standard}

3.1. Comparison between EN 1993-1-1 and ANSI/AISC 360-10. In the Eurocode EN 1993-1-1 [26], for a member under combined axial compression and biaxial bending, the following conditions should be satisfied:

$$
\begin{aligned}
& \frac{N}{\chi_{x} N_{R}}+k_{x x} \frac{M_{x}+\Delta M_{x}}{\chi_{\mathrm{LT}} M_{x, R}}+k_{x y} \frac{M_{y}+\Delta M_{y}}{M_{y, R}} \leq 1, \\
& \frac{N}{\chi_{y} N_{R}}+k_{y x} \frac{M_{x}+\Delta M_{x}}{\chi_{\mathrm{LT}} M_{x, R}}+k_{y y} \frac{M_{y}+\Delta M_{y}}{M_{y, R}} \leq 1,
\end{aligned}
$$

where $N, M_{x}$, and $M_{y}$ are the axial compression force and the maximum moments about the $x$ - and $y$-axes, respectively; $\Delta M_{x}$ and $\Delta M_{y}$ are the moments due to the shift 


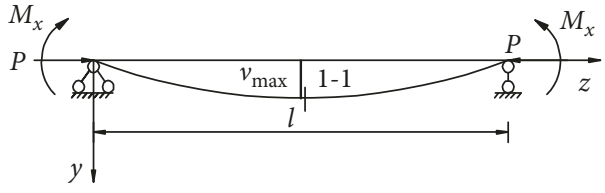

(a)

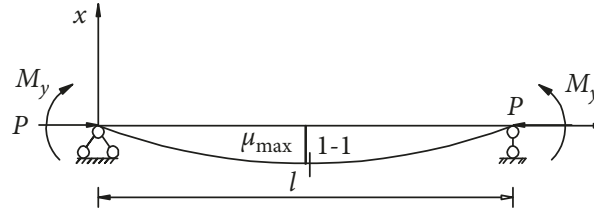

(b)

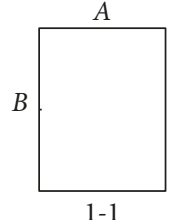

(c)

FIgURE 6: Flexural deformation about the (a) $x$-axis, (b) $y$-axis, and (c) cross section 1-1 at midlength.

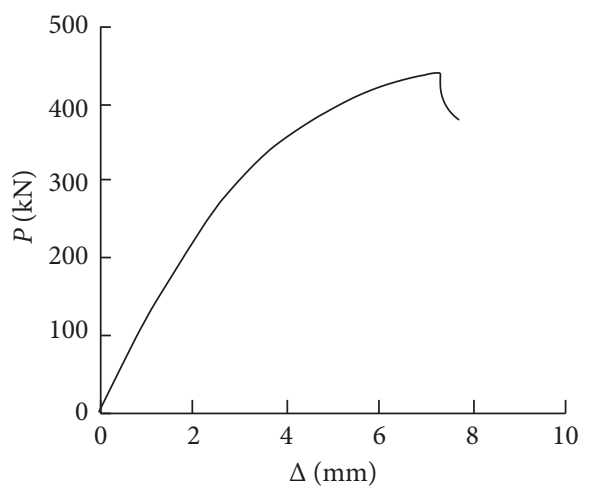

(a)

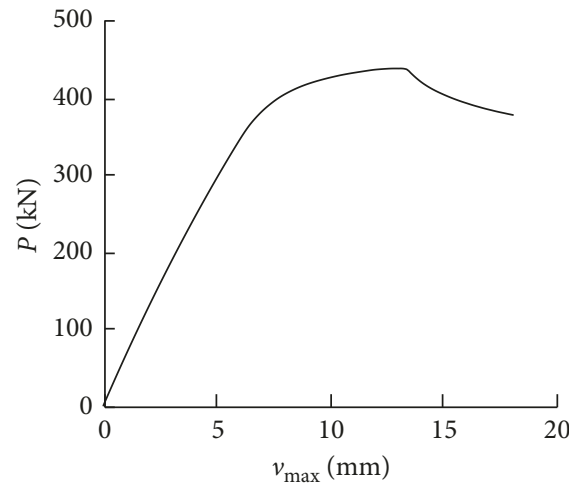

(c)

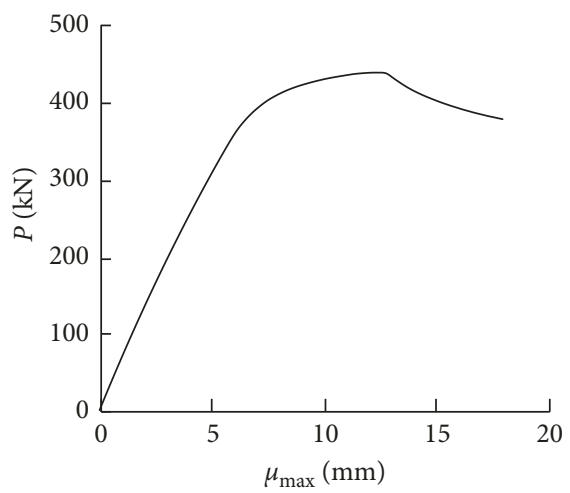

(b)

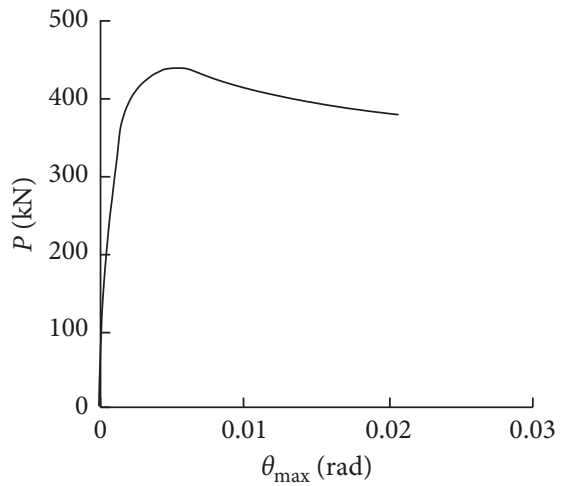

(d)

Figure 7: Load-displacement and load-rotation curves for the member S-40-40 (40, 40): (a) $P-\Delta$; (b) $P-\mu_{\max }$; (c) $P-v_{\max }$; (d) $P-\theta_{\max }$.

of the centroidal axis for class 4 sections; $N_{R}$ is the resistance to axial compression force; $M_{x, R}$ and $M_{y, R}$ are the resistances to bending moments about the $x$ - and $y$-axes, respectively; $\chi_{x}$ and $\chi_{y}$ are the reduction factors due to flexural buckling; $\chi_{\mathrm{LT}}$ is the reduction factor due to lateral torsional buckling; and $k_{x x}, k_{x y}, k_{y x}$, and $k_{y y}$ are the interaction factors.

This type of cross section studied in this paper is called class 4 section in EN 1993-1-1 [26]. For class 4 cross sections, these conditions are expressed as

$$
\begin{aligned}
& \frac{N}{\chi_{x} A_{\mathrm{eff}} f_{y}}+k_{x x} \frac{M_{x}+N e_{N, x}}{\chi_{\mathrm{LT}} W_{\mathrm{eff}, x} f_{y}}+k_{x y} \frac{M_{y}+N e_{N, y}}{W_{\mathrm{eff}, y} f_{y}} \leq 1, \\
& \frac{N}{\chi_{y} A_{\mathrm{eff}} f_{y}}+k_{y x} \frac{M_{x}+N e_{N, x}}{\chi_{\mathrm{LT}} W_{\mathrm{eff}, x} f_{y}}+k_{y y} \frac{M_{y}+N e_{N, y}}{W_{\mathrm{eff}, y} f_{y}} \leq 1,
\end{aligned}
$$

where $A_{\text {eff }}, W_{\text {eff, } x}$, and $W_{\text {eff, } y}$ are the effective cross-sectional area and effective section moduli about the $x$ - and $y$-axes, respectively, and $e_{N, x}$ and $e_{N, y}$ are the eccentricities with respect to the neutral axes.

According to the American National Standard ANSI/ AISC 360-10 [25], for members subjected to axial force and biaxial end moments, the following conditions should be met:

$$
\begin{array}{rlr}
\frac{P_{r}}{P_{n}}+\frac{8}{9}\left(\frac{M_{r x}}{M_{n x}}+\frac{M_{r y}}{M_{n y}}\right) \leq 1.0, & \text { when } \frac{P_{r}}{P_{n}} \geq 0.2, \\
\frac{P_{r}}{2 P_{n}}+\left(\frac{M_{r x}}{M_{n x}}+\frac{M_{r y}}{M_{n y}}\right) \leq 1.0, & \text { when } \frac{P_{r}}{P_{n}}<0.2,
\end{array}
$$

where $P_{r}$ is the required compressive strength; $P_{n}$ is the nominal compressive strength; $M_{r x}$ and $M_{r y}$ are the required 


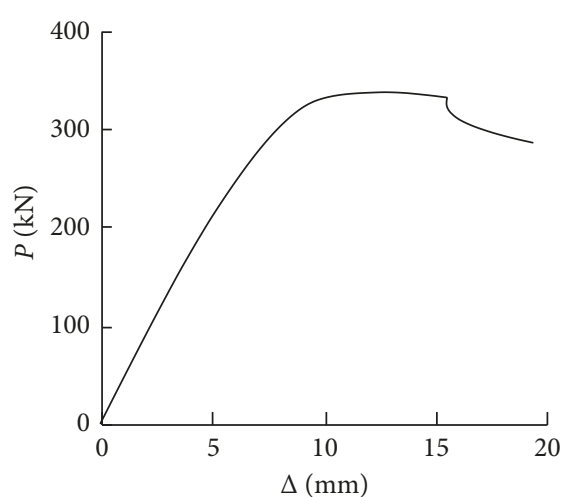

(a)

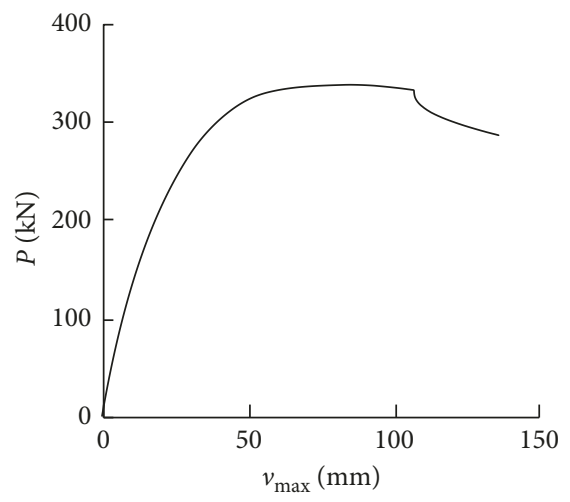

(c)

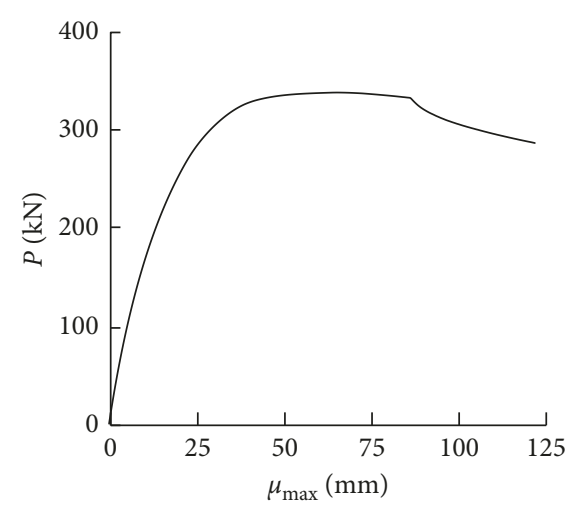

(b)

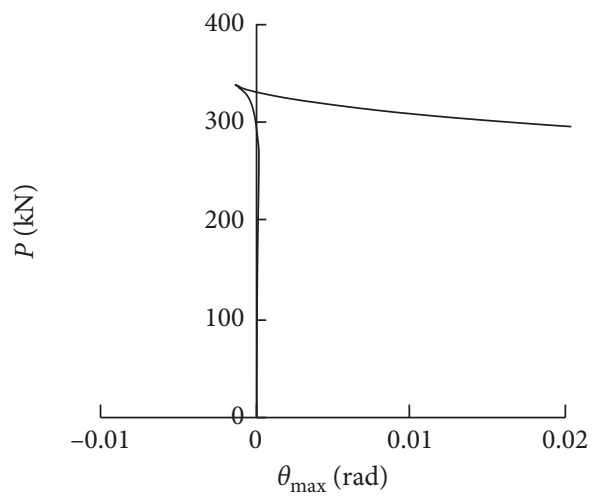

(d)

Figure 8: Load-displacement and load-rotation curves for the member S-50-100 (30, 35): (a) $P-\Delta$; (b) $P-\mu_{\max }$; (c) $P-v_{\max }$; (d) $P-\theta_{\max }$.

flexural strengths about the $x$ - and $y$-axes, respectively; and $M_{n x}$ and $M_{n y}$ are the nominal flexural strengths about the $x$ and $y$-axes, respectively.

In ANSI/AISC 360-10 [25], the cross section studied herein is called the slender section. For slender sections, $P_{n}$, $M_{n x}$, and $M_{n y}$ are determined on the basis of the effective width concept (see Section 3.2).

Comparing the two standards, the following can been found: (1) Linear interaction equations between the compression force and biaxial bending moments are used in both the standards, but two formulas in EN 1993-1-1 and only one formula in ANSI/AISC 360-10. (2) The second-order effect of $P-\delta$ is taken into account. It is considered in the interaction factors $k_{x x}, k_{x y}, k_{y x}$, and $k_{y y}$ in EN 1993-1-1, while it is included in the required flexural strengths $M_{r x}$ and $M_{r y}$ in ANSI/AISC 360-10, but the calculations of $k_{x x}, k_{x y}, k_{y x}$, and $k_{y y}$ are very complicated, while those of $M_{r x}$ and $M_{r y}$ are simple. (3) For a beam-column with a thin-walled section, both of the specifications adopt the effective width concept. In short, compared to EN 1993-1-1, the calculation according to ANSI/AISC 360-10 becomes much simpler. Hence, a comparison between ANSI/AISC 360-10 and the available experimental results and that between ANSI/AISC 360-10 and the numerical results will be made in the following sections to evaluate the applicability of ANSI/AISC 360-10 to HSS thin-walled beam-columns.
3.2. Comparison between ANSI/AISC 360-10 and the Available Experimental Results. When making a calculation by employing equations (5a) and (5b), the values of $P_{n}, M_{n x}$, $M_{n y}, M_{r x}$, and $M_{r y}$ must be determined first.

For slender sections, the nominal compressive strength $P_{n}$ should be taken as

$$
P_{n}=F_{\mathrm{cr}} A,
$$

where $F_{\text {cr }}$ is the flexural buckling stress and determined by

$$
\begin{array}{ll}
F_{\text {cr }}=Q\left[0.658^{Q F_{y} / F_{\mathrm{e}}}\right] F_{y}, & \text { for } \frac{K L}{r} \leq 4.71 \sqrt{\frac{E}{Q F_{y}}}, \\
F_{\text {cr }}=0.877 F_{\mathrm{e}}, & \text { for } \frac{K L}{r}>4.71 \sqrt{\frac{E}{Q F_{y}}},
\end{array}
$$

where $K$ is the effective length factor; $L$ is the laterally unbraced length of the member; $r$ is the governing radius of gyration; $F_{y}$ is the steel yield stress; $F_{\mathrm{e}}$ is the elastic critical buckling stress; and $Q$ is the reduction factor, for slender stiffened elements, $Q=Q_{a}$.

$Q_{a}$ is defined as

$$
Q_{a}=\frac{A_{\mathrm{e}}}{A}
$$

where $A_{\mathrm{e}}$ is the effective cross-sectional area based on effective width $b_{\mathrm{e}}$. 

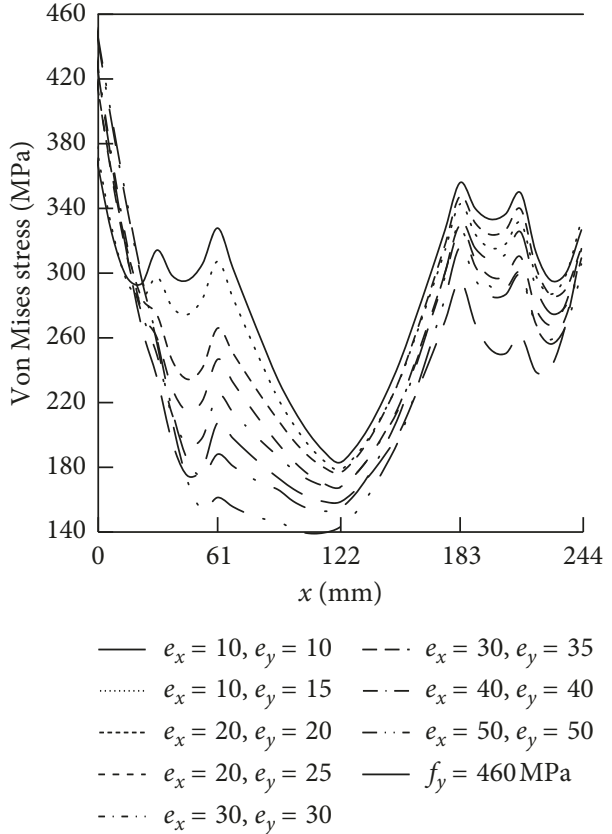

(a)

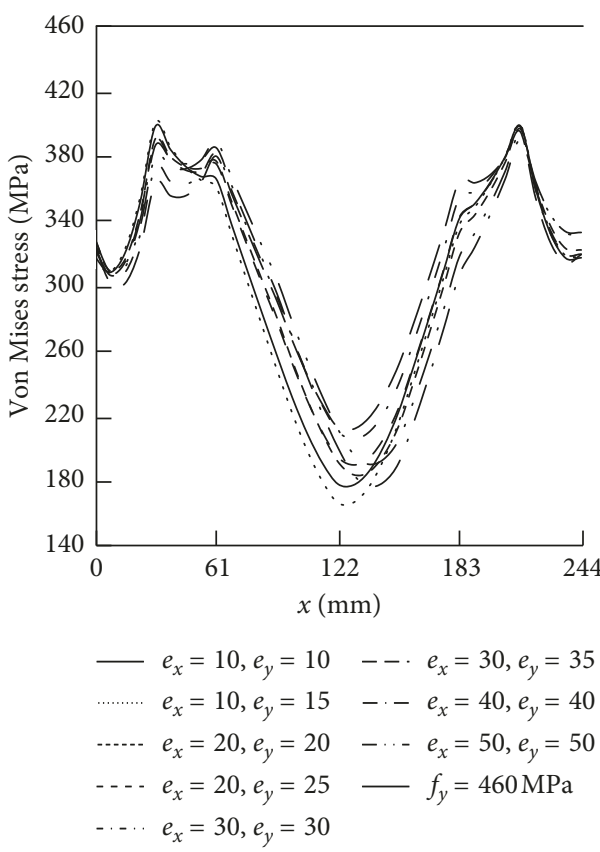

(c)

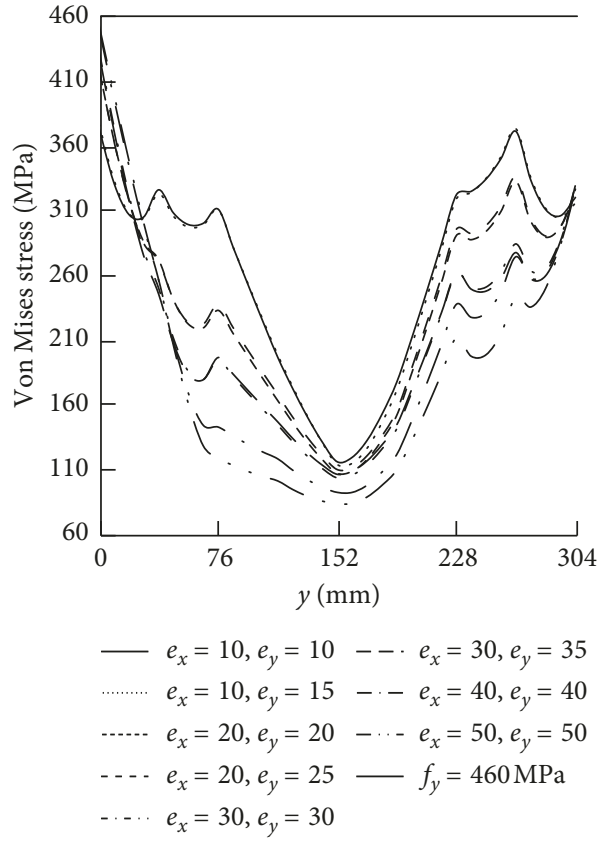

(b)

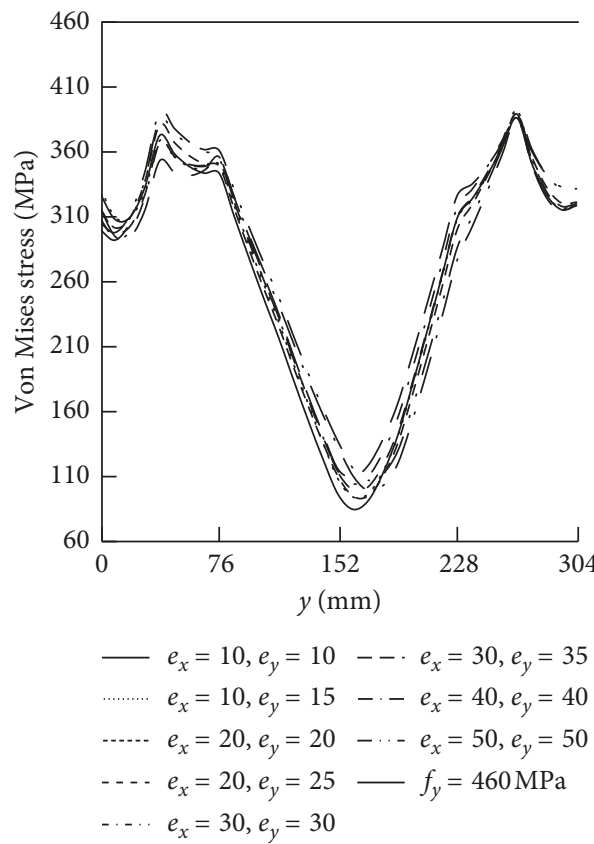

(d)

Figure 9: Von Mises stress distributions: (a) top flange; (b) left web; (c) bottom flange; (d) right web.

The effective width $b_{\mathrm{e}}$ is expressed as follows:

$$
b_{\mathrm{e}}=1.92 t \sqrt{\frac{E}{f_{1}}}\left[1-\frac{0.38}{(b / t)} \sqrt{\frac{E}{f_{1}}}\right] \leq b,
$$

where

$$
f_{1}=\frac{P_{n}}{A_{\mathrm{e}}} .
$$

It requires iteration to calculate the strength of a column according to equations (6)-(10). In order to simplify the calculation, $f_{1}$ is taken equal to $F_{y}$ as specified in ANSI/AISC
360-10 [25]. This will result in a slightly conservative estimate of available column strengths.

For slender sections, the nominal flexural strengths $M_{n x}$ and $M_{n y}$ shall be determined as follows:

$$
\begin{aligned}
& M_{n x}=F_{y} S_{e x}, \\
& M_{n y}=F_{y} S_{e y},
\end{aligned}
$$

where $S_{e x}$ and $S_{e y}$ are the effective section moduli about the $x$ - and $y$-axes and determined with the effective width $b_{\mathrm{e}}$, respectively. 


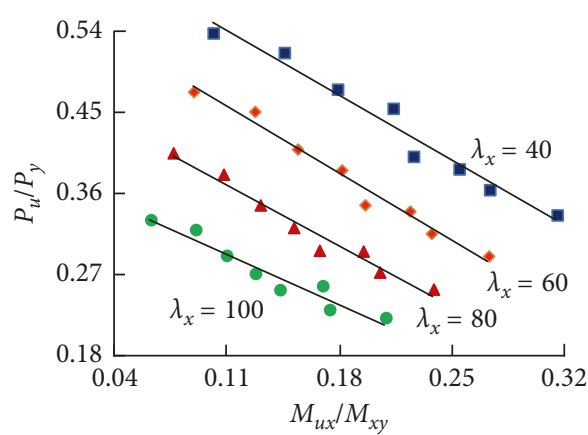

(a)

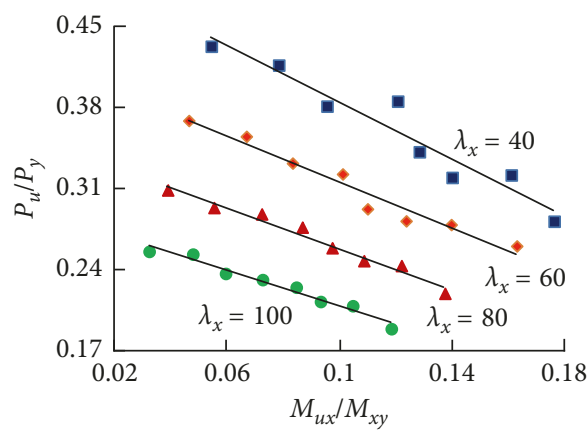

(c)

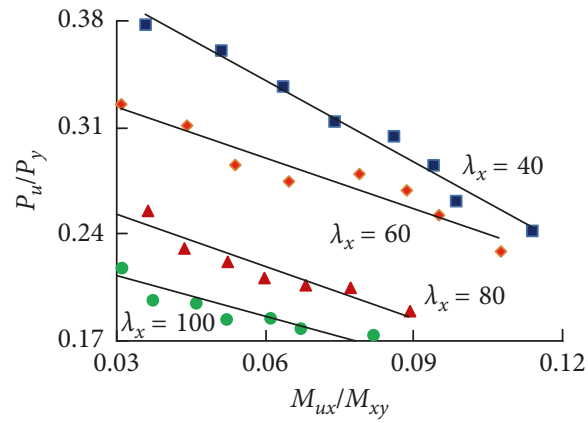

(e)

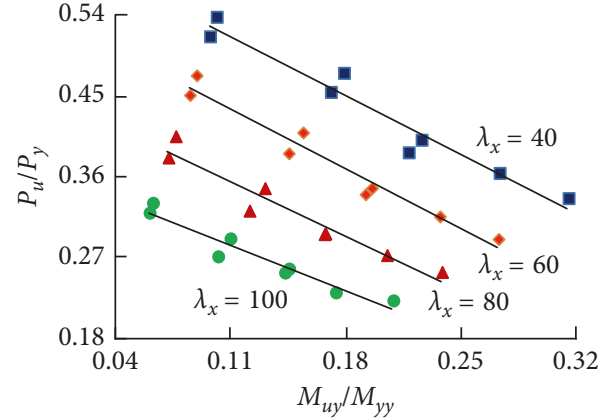

(b)

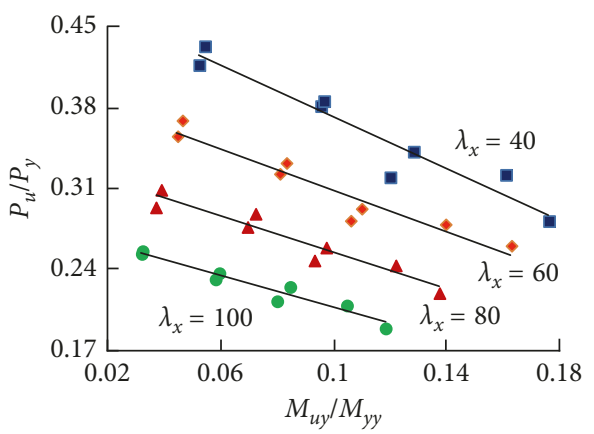

(d)

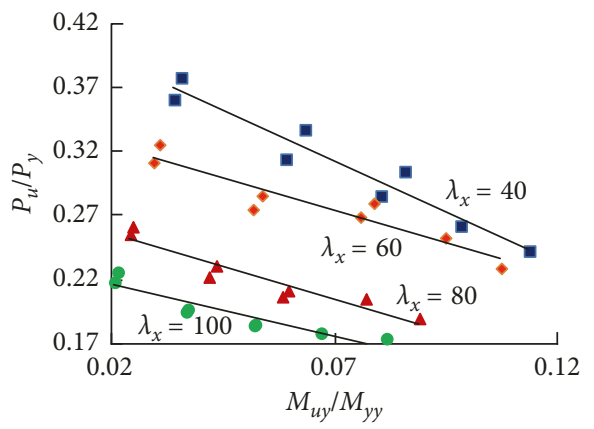

(f)

Figure 10: Interaction curves between $P_{u} / P_{y}$ and $M_{u x} / M_{x y}\left(\right.$ or $M_{u y} / M_{y y}$ ) for Q460 steel thin-walled square box beam-columns subjected to axial force and biaxial end moments. $P_{u} / P_{y}$ versus $M_{u x} / M_{x y}$ for (a) $b / t=40$; (c) $b / t=60$; (e) $b / t=80 . P_{u} / P_{y}$ versus $M_{u y} / M_{y y}$ for (b) $b / t=40$; (d) $b / t=60$; (f) $b / t=80$.

In order to consider the second-order effect of $P-\delta, M_{r x}$ and $M_{r y}$ are calculated using the following equations:

$$
\begin{aligned}
& M_{r x}=\frac{C_{m x} P_{r} e_{y}}{1-\left(P_{r} / P_{E x}\right)}, \\
& M_{r y}=\frac{C_{m y} P_{r} e_{x}}{1-\left(P_{r} / P_{E y}\right)},
\end{aligned}
$$

where $C_{m x}$ and $C_{m y}$ are the equivalent moment factors and $P_{E x}$ and $P_{E y}$ are Euler's critical loads.

Equations (5a) and (5b) are verified by the available experimental results (for slender box sections), as shown in Table 2. These experimental results are taken from different literatures with the measured steel yield stress of 268 741 MPa. By substituting these experimental values into the left-hand side of equations (5a) and (5b), the calculation results marked with "(1)" in Table 2 are obtained and are closer to 1 except for the three specimens with $\lambda_{x}=85$ [16] and the two specimens with $f_{y}=741 \mathrm{MPa}$ [12]. The average values of "(1)" in Table 2 are about 1.58 and 1.26 for the specimens with $\lambda_{x}=85\left(f_{y}=353 \mathrm{MPa}\right)$ and those with $f_{y}=741 \mathrm{MPa}$, respectively. Comparisons show that the standard ANSI/AISC 360-10 agrees, in most instances, very well with the experimental results. The ANSI/AISC 360-10 standard provides a better evaluation of the strengths of beam-columns with medium slenderness ratios and $f_{y}=248 \mathrm{MPa} \sim 373 \mathrm{MPa}$. It underestimates the strengths of beam-columns with $f_{y}=741 \mathrm{MPa}$ but overestimates the capacities of members with $f_{y}=568 \mathrm{MPa}$.

3.3. Comparison between ANSI/AISC 360-10 and the Numerical Results. The standard ANSI/AISC 360-10 is also compared with the numerical results, as shown in Figure 12. S-40 represents a series of square box beam-columns with $b / t=40$, 


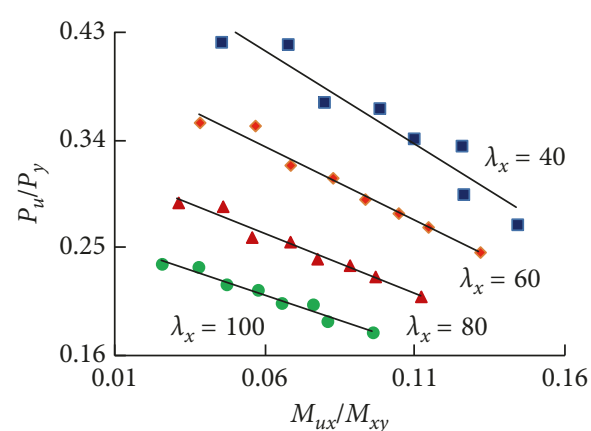

(a)

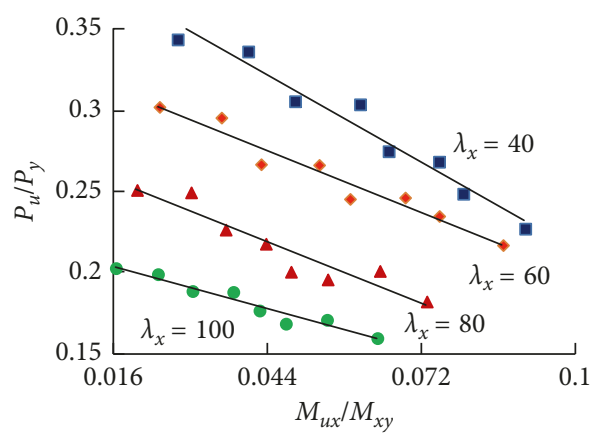

(c)

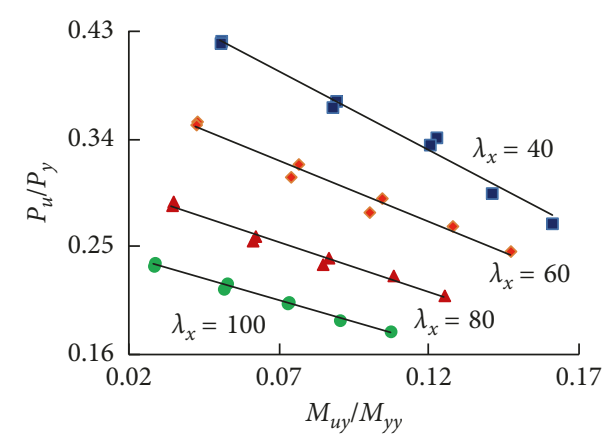

(b)

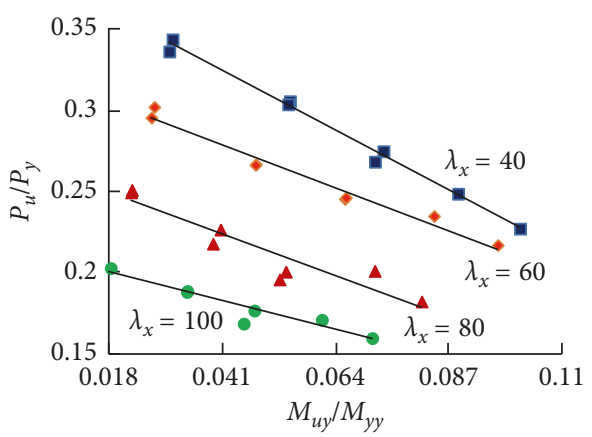

(d)

FIgURe 11: Interaction curves between $P_{u} / P_{y}$ and $M_{u x} / M_{x y}$ (or $M_{u y} / M_{y y}$ ) for Q460 steel thin-walled rectangular box beam-columns subjected to axial force and biaxial end moments. $P_{u} / P_{y}$ versus $M_{u x} / M_{x y}$ for (a) $b / t=60, h / t=75 ;(\mathrm{c}) b / t=80, h / t=100 . P_{u} / P_{y}$ versus $M_{u y} / M_{y y}$ for (b) $b / t=60, h / t=75$; (d) $b / t=80, h / t=100$.

and R-40-50 represents another series of rectangular ones with $b / t=40$ and $h / t=50$. The meaning of other symbols (S$50, \mathrm{~S}-60, \ldots)$ is the same as that of the two members. The maximum value of the left-hand side of equation (5) is 1.79, the minimum one is 0.83 , the average one is 1.09 , and the standard deviation is $14.8 \%$. For Q460 steel, the same phenomenon, as observed in the comparison between ANSI/ AISC 360-10 and the available experimental results, is found in Figure 12, and ANSI/AISC 360-10 severely underestimates the strengths of beam-columns with large slenderness ratios and small width-to-thickness ratios, such as S-40 with $\lambda_{x}=80$ and 100, S-60 with $\lambda_{x}=100, \mathrm{R}-40-50$ with $\lambda_{x}=80$ and 100, and R-50-62.5 with $\lambda_{x}=100$, especially for rectangular box sections. Except for these members, ANSI/AISC 360-10 gives good estimation of the strength of Q460 steel thin-walled box beam-columns subjected to axial force and biaxial end moments. It seems that ANSI/AISC 360-10 is not suitable for the rectangular box sections with a large depth-to-width ratio owing to the symmetry of the calculation formulas for the $x$ and $y$-axes.

\section{Proposal Strength Formulas for Q460 Steel Thin-Walled Box Beam-Columns Subjected to Axial Force and Biaxial End Moments}

4.1. Proposed Strength Formulas. The ANSI/AISC 360-10 standard is also suitable for Q460 steel thin-walled box beam-columns under biaxial bending over a wide range of column slenderness ratios. However, a complex calculation must be done to acquire the effective section properties to (1) calculate the effective width, (2) determine the centroidal axis of the effective section, and (3) calculate the effective section properties. Moreover, the available experimental results, together with the finite element results, show that ANSI/AISC 360-10 severely underestimates the strengths of beam-columns with large slenderness ratios $\left(f_{y}=353 \mathrm{MPa}\right.$ and $460 \mathrm{MPa}$ ) and slightly underestimates those of beam-columns with a yield stress of $741 \mathrm{MPa}$. As a result, a simple method, which uses the gross section properties, is proposed.

For a beam-column, the interaction formula between the axial compression load and the bending moment gives a theoretical basis to develop the strength formulas. As mentioned before, a linear relationship between $P_{u} / P_{y}$ and $M_{u x} / M_{x y}$ or between $P_{u} / P_{y}$ and $M_{u y} / M_{y y}$ is found, in most cases, for Q460 steel box cross-sectional biaxial bending beam-columns with slender plates. In addition, Salem et al. [17] investigated the ultimate strength of biaxially loaded slender I-section beam-columns made from mild steel and concluded that the linear interaction relationship could predict satisfactorily the strength of beam-columns with medium slenderness ratios. Therefore, the following linear interaction equation that is used in EN 1993-1-1 [26] and NAS AISI 2007 [33] is adopted:

$$
\frac{P}{P_{c}}+\frac{\alpha_{x} M_{x}}{M_{x c}}+\frac{\alpha_{y} M_{y}}{M_{y c}} \leq 1,
$$


TABLE 2: Comparisons between the available experimental results and those obtained according to ANSI/AISC 360-10 and the proposed formulas, respectively.

\begin{tabular}{|c|c|c|c|c|c|c|c|c|c|c|c|}
\hline Literature & $b / t$ & $h / t$ & $t(\mathrm{~mm})$ & $\lambda_{x}$ & $\lambda_{y}$ & $e_{x}(\mathrm{~mm})$ & $e_{y}(\mathrm{~mm})$ & $f_{y}\left(\mathrm{~N} / \mathrm{mm}^{2}\right)$ & $P_{\exp }(\mathrm{kN})$ & $\begin{array}{c}\text { ANSI/AISC } \\
360-10(1)\end{array}$ & $\begin{array}{c}\text { Proposed } \\
\text { formulas (2) }\end{array}$ \\
\hline \multirow{28}{*}{ Richard Liew et al. [16] } & 29.5 & 29.8 & 3.05 & 85.3 & 85.4 & 15 & 0 & 353 & 209.99 & 1.35 & 1.09 \\
\hline & 29.5 & 29.8 & 3.05 & 85.3 & 85.4 & 5 & 10 & 353 & 224.62 & 1.57 & 1.19 \\
\hline & 29.2 & 29.2 & 3.05 & 87.1 & 83.3 & 5 & 5 & 353 & 254.37 & 1.81 & 1.20 \\
\hline & 43.9 & 44.6 & 3.05 & 57.2 & 57.6 & 15 & 0 & 353 & 325.30 & 1.15 & 0.98 \\
\hline & 44.2 & 44.2 & 3.05 & 57.5 & 57.3 & 5 & 15 & 353 & 312.24 & 1.13 & 1.02 \\
\hline & 44.2 & 44.2 & 3.05 & 57.5 & 57.3 & 15 & 15 & 353 & 286.74 & 1.21 & 1.09 \\
\hline & 52.4 & 52.4 & 3.05 & 48.8 & 48.7 & 20 & 0 & 353 & 324.73 & 1.06 & 0.91 \\
\hline & 52.4 & 52.4 & 3.05 & 48.8 & 48.7 & 15 & 10 & 353 & 338.72 & 1.14 & 1.03 \\
\hline & 52.1 & 51.8 & 3.05 & 49.1 & 48.8 & 10 & 10 & 353 & 348.63 & 1.11 & 1.00 \\
\hline & 64.2 & 64.2 & 1.87 & 64.4 & 64.2 & 0 & 10 & 268 & 114.39 & 0.95 & 0.96 \\
\hline & 64.2 & 63.7 & 1.87 & 65.7 & 63.4 & 10 & 5 & 268 & 108.18 & 1.06 & 0.99 \\
\hline & 64.8 & 64.2 & 1.87 & 64.4 & 64.2 & 15 & 15 & 268 & 83.25 & 0.98 & 0.97 \\
\hline & 75.9 & 75.9 & 1.86 & 54.8 & 54.7 & 15 & 0 & 268 & 118.11 & 1.05 & 1.10 \\
\hline & 75.9 & 75.3 & 1.86 & 55.7 & 54.7 & 15 & 10 & 268 & 109.24 & 1.08 & 1.19 \\
\hline & 75.5 & 75.3 & 1.86 & 55.7 & 54.7 & 15 & 15 & 268 & 102.63 & 1.06 & 1.19 \\
\hline & 86 & 85.6 & 1.85 & 48.7 & 48.6 & 0 & 20 & 268 & 117.66 & 0.92 & 1.33 \\
\hline & 85 & 86.1 & 1.85 & 48.5 & 48.8 & 20 & 10 & 268 & 115.30 & 1.12 & 1.44 \\
\hline & 86 & 85.6 & 1.85 & 48.7 & 48.6 & 15 & 15 & 268 & 111.59 & 0.90 & 1.43 \\
\hline & 40.3 & 53.7 & 2.98 & 51 & 62.4 & 19 & 0 & 293 & 261.76 & 1.02 & 0.96 \\
\hline & 39.6 & 54 & 2.98 & 50.1 & 63.3 & 20 & 10 & 293 & 260.37 & 1.14 & 1.11 \\
\hline & 39.6 & 54 & 2.98 & 50.1 & 63.3 & 20 & 20 & 293 & 236.70 & 1.13 & 1.11 \\
\hline & 39.9 & 53.7 & 2.98 & 50.2 & 62.8 & 10 & 20 & 293 & 268.97 & 1.13 & 1.10 \\
\hline & 39.9 & 54 & 2.98 & 50 & 62.8 & 0 & 20 & 293 & 311.95 & 1.21 & 1.08 \\
\hline & 70 & 86.1 & 1.87 & 49.6 & 61.7 & 20 & 0 & 268 & 105.21 & 1.03 & 1.03 \\
\hline & 70 & 86.1 & 1.87 & 49.6 & 61.7 & 20 & 10 & 268 & 97.14 & 1.02 & 1.07 \\
\hline & 70 & 86.1 & 1.87 & 49.6 & 61.7 & 20 & 20 & 268 & 93.72 & 1.05 & 1.14 \\
\hline & 70 & 86.1 & 1.87 & 49.6 & 61.7 & 10 & 20 & 268 & 102.72 & 0.98 & 1.09 \\
\hline & 70 & 86.1 & 1.87 & 49.6 & 61.7 & 0 & 20 & 268 & 114.52 & 0.90 & 1.03 \\
\hline \multirow{11}{*}{ Usami and Fukumoto [11] } & 29.3 & 22.0 & 4.46 & 39.6 & 29.3 & 0 & 10.4 & 568 & 742 & 0.98 & 0.95 \\
\hline & 43.9 & 32.9 & 4.47 & 40 & 29.6 & 0 & 15.7 & 568 & 906 & 0.98 & 0.91 \\
\hline & 58.2 & 43.7 & 4.48 & 40 & 30.4 & 0 & 20.9 & 568 & 932 & 0.90 & 0.86 \\
\hline & 44.4 & 33.3 & 4.45 & 40 & 29.5 & 0 & 31.4 & 568 & 743 & 0.97 & 0.93 \\
\hline & 29.5 & 22.1 & 4.42 & 64.4 & 45.6 & 0 & 10.4 & 568 & 524 & 0.95 & 0.83 \\
\hline & 43.9 & 32.9 & 4.5 & 64.9 & 47.9 & 0 & 15.7 & 568 & 740 & 1.03 & 0.90 \\
\hline & 58.2 & 43.7 & 4.48 & 64.6 & 48.8 & 0 & 20.8 & 568 & 743 & 0.87 & 0.82 \\
\hline & 43.9 & 32.9 & 4.5 & 64.9 & 47.9 & 0 & 31.4 & 568 & 593 & 0.97 & 0.85 \\
\hline & 58.2 & 43.7 & 4.48 & 64.6 & 48.8 & 0 & 41.6 & 568 & 639 & 0.89 & 0.83 \\
\hline & 44.2 & 33.2 & 4.47 & 39.6 & 36.8 & 0 & 20.4 & 568 & 914 & 0.98 & 0.81 \\
\hline & 58.2 & 43.7 & 4.48 & 40 & 37.8 & 0 & 26.9 & 568 & 986 & 0.95 & 0.81 \\
\hline \multirow{3}{*}{ Usami and Fukumoto [12] } & 22.1 & 16.6 & 6.01 & 48.8 & 39.0 & 0 & 10.7 & 741 & 1299 & 1.14 & 1.01 \\
\hline & 27.1 & 20.3 & 6.01 & 49 & 39.3 & 0 & 13.1 & 741 & 1681 & 1.33 & 1.15 \\
\hline & 33.1 & 24.8 & 6.01 & 49.2 & 39.5 & 0 & 16.0 & 741 & 1877 & 1.30 & 1.11 \\
\hline \multirow{3}{*}{ Chiew et al. [2] } & 40 & 40 & 2 & 33.7 & 33.7 & 0 & 8.2 & 261.2 & 136.34 & 1.12 & 1.25 \\
\hline & 57.1 & 57.1 & 1.4 & 33.7 & 33.7 & 0 & 8.2 & 253.6 & 71.12 & 1.03 & 1.17 \\
\hline & 80 & 80 & 1 & 33.7 & 33.7 & 0 & 8.2 & 248.6 & 36.88 & 0.96 & 1.38 \\
\hline \multirow{3}{*}{ Pavlovčič et al. [6] } & 44 & 39 & 4 & 61.4 & 56.2 & 0 & 20 & 373.4 & 566.76 & 1.18 & 1.09 \\
\hline & 44 & 39 & 4 & 61.4 & 56.2 & 0 & 60 & 373.4 & 384.85 & 1.14 & 1.10 \\
\hline & 44 & 39 & 4 & 61.4 & 56.2 & 0 & 200 & 373.4 & 206.09 & 1.18 & 1.21 \\
\hline Average & & & & & & & & & & 1.08 & 1.06 \\
\hline Standard deviation (\%) & & & & & & & & & & 17.2 & 15.7 \\
\hline
\end{tabular}

$(1)=\left(P_{\exp } / P_{n}\right)+(8 / 9)\left[\left(P_{\exp } e_{y} /\left(M_{n x}\left(1-P_{\exp } / P_{E x}\right)\right)\right)+\left(P_{\exp } e_{x} /\left(M_{n y}\left(1-P_{\exp } / P_{E y}\right)\right)\right)\right]$

$(2)=\left(P_{\exp } / N_{m}\right)+\left(P_{\exp } e_{y} /\left(\alpha W_{x} f_{y}\left(1-\left(\varphi_{x} P_{\exp } / N_{E x}^{\prime}\right)\right)\right)+\left(P_{\exp } e_{x} /\left(\alpha W_{y} f_{y}\left(1-\left(\varphi_{y} P_{\exp } / N_{E y}^{\prime}\right)\right)\right)\right) ; f_{y}\right.$ is the measured yield stress.

where $P$ is the axial force; $P_{c}$ is the allowable pure axial force; $M_{x c}$ and $M_{y c}$ are the allowable pure bending moments about the $x$ - and $y$-axes, respectively; and $\alpha_{x}$ and $\alpha_{y}$ are the amplification factors for bending moments.
When equation (13) is used for class 4 cross sections in EN 1993-1-5 [27], it is changed into equations (4a) and (4b).

When equation (13) is used for cold-formed sections in NAS AISI 2007 [33], it is modified as follows: 


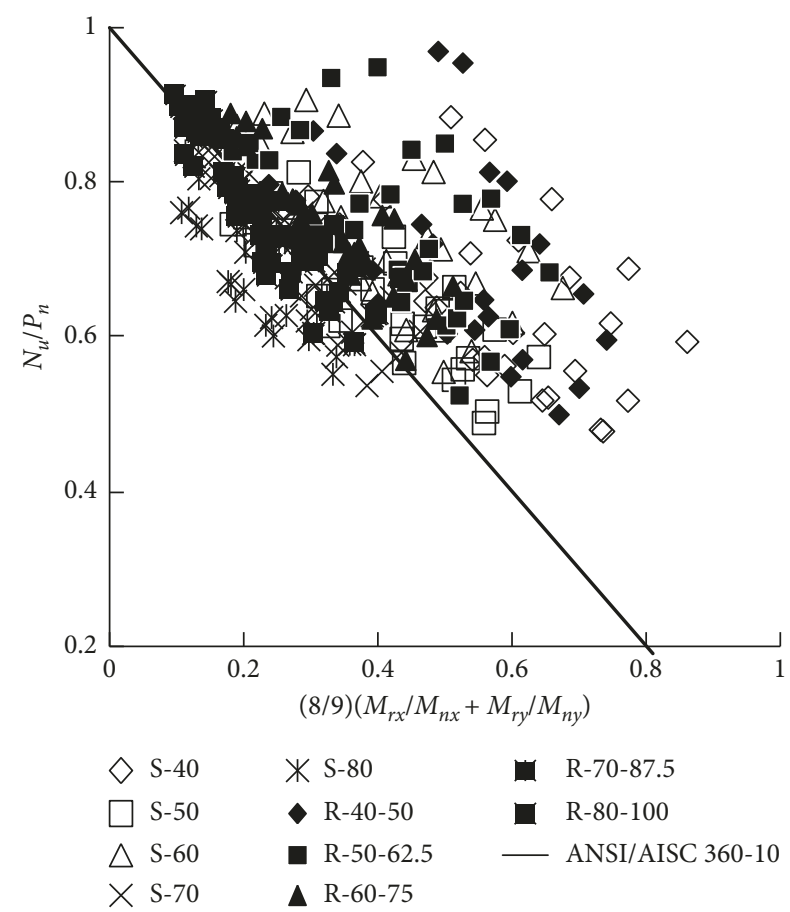

Figure 12: Comparison of formula (5) and numerical results.

$$
\frac{N}{\varphi_{\min } A_{\mathrm{e}} f_{y}}+\frac{\beta_{m x} M_{x}}{W_{e x} f_{y}\left(1-\left(N / N_{E x}\right)\right)}+\frac{\beta_{m y} M_{y}}{W_{e y} f_{y}\left(1-\left(N / N_{E y}\right)\right)} \leq 1,
$$

where $\beta_{m x}$ and $\beta_{m y}$ are the equivalent moment factors about the $x$ - and $y$-axes, respectively; $\varphi_{\min }$ is the smaller one of $\varphi_{x}$ and $\varphi_{y} ; W_{e x}$ and $W_{e y}$ are the effective section moduli about the $x$ - and $y$-axes, respectively; and $N_{E x}$ and $N_{E y}$ are Euler's critical loads.

Also, the effective section properties are adopted in equation (14), thus leading to a complex calculation. Hence, a simple method is proposed in the following section.

Being in the elastic range is found when the Q460 steel beam-columns reach the ultimate carrying capacities from the von Mises stress distributions in Figure 9. The same phenomenon was also discovered by Shen [22]. A simple formula was proposed by Shen [22] to evaluate the strength of HSS rectangular cross-sectional beam-columns with slender webs under uniaxial bending. The formula is expressed as follows:

$$
\frac{N}{\varphi_{x} A}+\frac{\beta_{m x} M_{x}}{W_{x}\left(1-\left(\varphi_{x} N / N_{E x}^{\prime}\right)\right)} \leq \alpha f_{y}
$$

where $\varphi_{x}$ is the strength reduction factor of a centrally loaded member about the $x$-axis; $N_{E x}^{\prime}$ is a parameter, $N_{E x}^{\prime}=$ $\pi^{2} E A /\left(1.1 \lambda_{x}^{2}\right)$ (where 1.1 is a partial factor for resistance); $\alpha$ is the modification factor for the steel yield strength; and $f_{y}$ is the steel yield strength.

In addition, for box-section beam-columns under biaxial bending, as mentioned in Section 2.2.1, the bending deflections about the $x$ - and $y$-axes and axial compressive displacement are two major deformations and the rotation about the $z$-axis is very small. For this reason, using equation (14) as the reference, equation (15) can be modified for the ultimate strength of Q460 steel thin-walled box-section columns subjected to axial compressive force and major- and minoraxis bending moments. The modified equation is expressed as follows:

$$
\frac{N}{\varphi_{\min } A}+\frac{\beta_{m x} M_{x}}{W_{x}\left(1-\left(\varphi_{x} N / N_{E x}^{\prime}\right)\right)}+\frac{\beta_{m y} M_{y}}{W_{y}\left(1-\left(\varphi_{y} N / N_{E y}^{\prime}\right)\right)} \leq \alpha f_{y},
$$

where $\varphi_{y}$ is the strength reduction factor of a centrally loaded member about the $y$-axis and $N_{E y}^{\prime}$ is a parameter, $N_{E y}^{\prime}=\pi^{2} E A /\left(1.1 \lambda_{y}^{2}\right)$.

The ultimate carrying capacity of columns with nonslender sections and made from Q345, Q390, Q420, and SM58 steels (the nominal yield stresses are $345 \mathrm{MPa}, 390 \mathrm{MPa}$, $420 \mathrm{MPa}$, and $460 \mathrm{MPa}$, respectively) was simulated to determine which column curve should be used when calculating the values of $\varphi_{x}$ and $\varphi_{y}$ by Shen [9]. The results show that the curve $a$ in GB 50017-2003 [30] should be adopted. Degée et al. [3] also suggested that the curve $a$ in EN 1993-1-1 [26] should be employed when the local and global interaction buckling of welded box-section compression members fabricated from S355, S460, and S690 steels (the nominal yield stresses are $355 \mathrm{MPa}, 460 \mathrm{MPa}$, and $690 \mathrm{MPa}$, respectively) was investigated. There is a little difference in the value of the equivalent imperfection between GB 50017-2003 and EN 1993-1-1 when determining the stability reduction factor, but the values of three design column curves $a, b$, and $c$ in GB 50017-2003 are very close to those of three column curves $a, b$, and $c$ in EN 1993-1-1. As a result, in equation (16), $\varphi_{x}$ and $\varphi_{y}$ are obtained according to $\lambda_{x} \sqrt{f_{y} / 235}$ and $\lambda_{y} \sqrt{f_{y} / 235}$, respectively, and the column curve a recommended in the Chinese Code GB 50017-2003 [30].

Besides, in equation (16), $\beta_{m x}=\beta_{m y}=1.0$ for a beamcolumn with equal end flexural moments; $N$ is taken as $P_{u}$; $M_{x}$ as $M_{u x}$, i.e., $P_{u} e_{y}$; and $M_{y}$ as $M_{u y}$, i.e., $P_{u} e_{x}$; and then the numerical result, $P_{u}$, is substituted into equation (16). After finishing all these, the modified factor, $\alpha$, can be obtained by dividing the left-hand side of equation (16) by the steel yield strength, $f_{y}$.

The ultimate strength of Q460 steel welded thin-walled box cross-sectional beam-columns is related to the slenderness ratios, $\lambda_{x}$ and $\lambda_{y}$, width-to-thickness ratio, $b / t$, and depth-to-thickness ratio, $h / t$. For rectangular box sections, in this paper, the depth-to-width ratio is a constant of 1.25; hence, $h / t$ is related to $b / t$ and, similarly, $\lambda_{y}$ to $\lambda_{x}$. Therefore, the modification factor, $\alpha$, may be treated as a function of only two variables $b / t$ and $\lambda_{x}$. The study shows that, in most cases, the nondimensional ultimate carrying capacity, $P_{u} / A f_{y}\left(P_{u}\right.$ is the ultimate carrying capacity), is nearly linear to each of $\lambda_{x}$ and $b / t$, respectively. By using a curve-fitting technique, the following equation can be obtained:

$$
\alpha=1.2+0.003 \lambda_{x}-\frac{0.011 b}{t} .
$$

Substituting the numerical results and equation (17) into equation (16) and introducing the symbols $N_{m}=\alpha \varphi_{\min } A f_{y}$, 


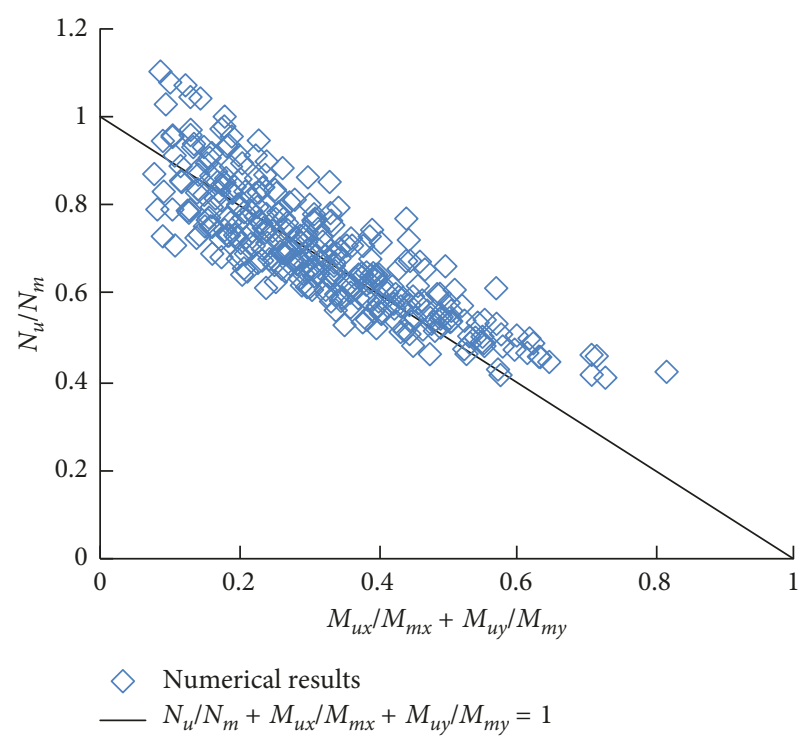

Figure 13: Comparison of formula (16) and numerical results.

$M_{m x}=\alpha W_{x}\left(1-\left(\varphi_{x} N / N_{E x}^{\prime}\right)\right) f_{y}, \quad$ and $\quad M_{m y}=\alpha W_{y}(1-$ $\left.\left(\varphi_{y} N / N_{E y}^{\prime}\right)\right) f_{y}$, the ratios of the left side to the right side of equation (16) are obtained and plotted in Figure 13. In Figure 13, the ratio values change over a range of 0.818 to 1.239 , with an average value of 1.015 and a standard deviation of $7.92 \%$. Hence, equation (16) coincides quite well with the numerical results.

4.2. Verification of the Proposed Formulas. The available experimental results, as listed in Table 2, are also used to verify the proposed formulas. In order to compare them easily, equation (16) is changed into the following equation:

$$
\begin{gathered}
\frac{N}{\varphi_{\min } A \alpha f_{y}}+\frac{\beta_{m x} M_{x}}{W_{x} \alpha f_{y}\left(1-\left(\varphi_{x} N / N_{E x}^{\prime}\right)\right)} \\
+\frac{\beta_{m y} M_{y}}{W_{y} \alpha f_{y}\left(1-\left(\varphi_{y} N / N_{E y}^{\prime}\right)\right)} \leq 1 .
\end{gathered}
$$

Similarly, substituting the experimental results and equation (17) into the left-hand side of equation (18), the calculation results labeled with "(2)" in Table 2 are obtained. These values are very close to 1 except for four beam-columns with larger width-to-thickness ratios $(b / t=80$ and 85$)$ and fabricated from the mild steels with $f_{y}=248.6 \mathrm{MPa}$ and $f_{y}=268 \mathrm{MPa}$. For the four members, the average value of "(2)" in Table 2 is about 1.40 and equation (18) gives a low estimate of their strengths. In general, the simple formulas proposed herein give a reasonably accurate estimate of the strength of the beam-columns over a wide range of the steel yield stress, and for the most part, they are applicable to the thin-walled box beam-columns made from both mild and high-strength steels. Meanwhile, a standard deviation of $15.7 \%$ listed in Table 2, compared to $17.2 \%$, shows that the simple formulas achieve the same level of accuracy as the American Standard ANSI/AISC 360-10. For the HSS specimens with $f_{y}=741 \mathrm{MPa}$, the simple formulas, based on the numerical results, provide a good estimate of their strengths; for those with $f_{y}=568 \mathrm{MPa}$, they give a slight overestimate; however, all these specimens were loaded with uniaxial eccentricity, so more experiments, on the HSS beam-columns under biaxial bending, are needed to be conducted to verify the proposed formulas.

\section{Conclusions}

The behavior and strength of Q460 steel welded thin-walled box-section beam-columns under combined compression force and biaxial bending are analyzed by an established FE model. The American Specification ANSI/AISC 360-10 is verified with the numerical results and the available experimental results. Simple and effective formulas are proposed for predicting the maximum strength of the beamcolumns. Also, the proposed formulas are compared with the available experimental results. Some conclusions can be drawn from this paper:

(1) The established FE model can simulate the localoverall interaction buckling behaviors of the beamcolumns subjected to combined axial compression force and biaxial bending.

(2) It is observed that, in most cases, the von Mises stresses are much smaller than the steel yield strength when the beam-columns reach the ultimate loads.

(3) The correlation curves between the axial force $P_{u} / P_{y}$ and the flexural moment $M_{u x} / M_{x y}\left(\right.$ or $\left.M_{u y} / M_{y y}\right)$ of Q460 steel thin-walled box-section beam-columns under compression and biaxial bending moments are nearly linear.

(4) The code ANSI/AISC 360-10 agrees very well with both the numerical and experimental results except for two types of beam-columns, one with large slenderness ratios and the other made from the HSS with a yield stress of $741 \mathrm{MPa}$. For the former, ANSI/ AISC 360-10 seriously underestimates the strengths, and for the latter, it slightly underestimates.

(5) After having been modified, the formula proposed for the local-overall interactive buckling strength of HSS box beam-columns under uniaxial bending can be used for Q460 steel box beam-columns under biaxial bending. The proposed modified formulas are in good agreement with the numerical and experimental results over a wide range of the steel yield stress. The maximum of nominal yield stress in the available tests is $690 \mathrm{MPa}$, and hence, $f_{y} \leq 690 \mathrm{MPa}$ has been adopted as a limit of application of the proposed formulas. $h / b=1.0$ or 1.25 in this study, and $h / b$ or $b / h=1.0 \sim 1.33$ in the available experiments $[2,6,11,12,16]$. In practical projects, for economic consideration, $h / b$ or $b / h$ of box sections should be close to or slightly greater than 1 to avoid that the carrying capacity in one direction is much higher than that in the other direction. Therefore, the modification factor $\alpha$, which should be a function of 
$b / t, h / t, \lambda_{x}$, and $\lambda_{y}$, can be simplified as a function of $b / t$ and $\lambda_{x}$, as given in equation (17). But the available experimental data on HSSs are very limited, and more experiments are needed to be conducted to verify these proposed formulas.

\section{Data Availability}

The data used to support the findings of this study are available from the author upon request.

\section{Conflicts of Interest}

The author declares that there are no conflicts of interest.

\section{Acknowledgments}

The research reported in this paper was supported by $\mathrm{Na}$ tional Science Basic Research Plan in Shaanxi Province, China (Grant no. 2018JM5079), and the Steel Structure Innovation Team of Xi'an University of Architecture and Technology, China. Their financial support is highly appreciated.

\section{References}

[1] L. Bai and M. A. Wadee, "Slenderness effects in thin-walled I-section struts susceptible to local-global mode interaction," Engineering Structures, vol. 124, pp. 128-141, 2016.

[2] S. P. Chiew, S. L. Lee, and N. E. Shanmugam, "Experimental study of thin-walled steel box columns," Journal of Structural Engineering, vol. 113, no. 10, pp. 2208-2220, 1987.

[3] H. Degée, A. Detzel, and U. Kuhlmann, "Interaction of global and local buckling in welded RHS compression members," Journal of Constructional Steel Research, vol. 64, no. 7-8, pp. 755-765, 2008.

[4] Y. B. Kwon, N. G. Kim, and G. J. Hancock, "Compression tests of welded section columns undergoing buckling interaction," Journal of Constructional Steel Research, vol. 63, no. 12, pp. 1590-1602, 2007.

[5] E. L. Liu and M. A. Wadee, "Geometric factors affecting I-section struts experiencing local and strong-axis global buckling mode interaction," Thin-Walled Structures, vol. 109, pp. 319-331, 2016.

[6] L. Pavlovčič, B. Froschmeier, U. Kuhlmann, and D. Beg, "Finite element simulation of slender thin-walled box columns by implementing real initial conditions," Advances in Engineering Software, vol. 44, no. 1, pp. 63-74, 2012.

[7] M. Pircher, M. D. O'Shea, and R. Q. Bridge, "The influence of the fabrication process on the buckling of thin-walled steel box sections," Thin-Walled Structures, vol. 40, no. 2, pp. 109-123, 2002.

[8] H. X. Shen, "Ultimate capacity of welded box section columns with slender plate elements," Steel \& Composite Structures, vol. 13, no. 1, pp. 15-33, 2012.

[9] H. X. Shen, "On the direct strength and effective yield strength method design of medium and high strength steel welded square section columns with slender plate elements," Steel and Composite Structures, vol. 17, no. 4, pp. 497-516, 2014.

[10] J. J. Shen, M. A. Wadee, and A. J. Sadowski, "Interactive buckling in long thin-walled rectangular hollow section struts," International Journal of Non-Linear Mechanics, vol. 89, pp. 43-58, 2017.
[11] T. Usami and Y. Fukumoto, "Welded box compression members," Journal of Structural Engineering, vol. 110, no. 10, pp. 2457-2470, 1984.

[12] T. Usami and Y. Fukumoto, "Local and overall buckling of welded box columns," Journal of Structural Division, vol. 108, no. 3, pp. 525-542, 1982.

[13] J. J. Shen and M. A. Wadee, "Length effects on interactive buckling in thin-walled rectangular hollow section struts," Thin-Walled Structures, vol. 128, pp. 152-170, 2018.

[14] J. J. Shen and M. A. Wadee, "Imperfection sensitivity of thinwalled rectangular hollow section struts susceptible to interactive buckling," International Journal of Non-Linear Mechanics, vol. 99, pp. 112-130, 2018.

[15] S. L. Lee, N. E. Shanmugam, and S. P. Chiew, "Thin-walled box columns under arbitrary end loads," Journal of Structural Engineering, vol. 114, no. 6, pp. 1390-1402, 1988.

[16] J. Y. Richard Liew, N. E. Shanmugam, and S. L. Lee, "Behavior of thin-walled steel box columns under biaxial loading," Journal of Structural Engineering, vol. 115, no. 12, pp. 30763094, 1989.

[17] A. H. Salem, M. El Aghoury, F. F. El Dib, and M. T. Hanna, "Strength of biaxially loaded slender I-section beam-columns," Canadian Journal of Civil Engineering, vol. 34, no. 2, pp. 219-227, 2007.

[18] N. E. Shanmugam, S. P. Chiew, and S. L. Lee, "Strength of thin-walled square steel box columns," Journal of Structural Engineering, vol. 113, no. 4, pp. 818-831, 1987.

[19] N. E. Shanmugam, J. Y. Richard Liew, and S. L. Lee, "Thinwalled steel box columns under biaxial loading," Journal of Structural Engineering, vol. 115, no. 11, pp. 2706-2726, 1989.

[20] H. X. Shen and C. H. Yang, "Analysis of local-overall interaction buckling of high-strength steel welded I-section compression-bending members," Building Structure, vol. 43, no. 22, pp. 33-38, 2013, in Chinese.

[21] H. X. Shen and X. Liu, "Analysis on the ultimate carrying capacities of local-overall interaction of high-strength steel welded square-box section columns loaded with eccentricity," Building Structure, vol. 44, no. 4, pp. 35-38, 2014, in Chinese.

[22] H. X. Shen, "Behavior of high-strength steel welded rectangular section beam-columns with slender webs," Thin-Walled Structures, vol. 88, pp. 16-27, 2015.

[23] H. X. Shen and K. X. Zhao, "Finite element analysis of local and overall flexural-torsional interactive buckling of Q460 high strength steel welded I-section beam-columns," Progress in Steel Building Structures, vol. 17, no. 4, pp. 1-9, 2015, in Chinese.

[24] GB 50017-2017, Standard for Design of Steel Structures, Guobiao Standards, Beijing, China, 2017.

[25] ANSI/AISC 360-10, Specification for Structural Steel Buildings, AISC, Chicago, IL, USA, 2010.

[26] EN 1993-1-1, Eurocode 3: Design of Steel Structures-Part 1-1: General Rules and Rules for Buildings, European Committee for Standardization, Brussels, Belgium, 2005.

[27] EN 1993-1-5, Eurocode 3-Design of Steel Structures-Part 1-5: Plated Structural Elements, European Committee for Standardization, Brussels, Belgium, 2007.

[28] ANSYS Inc, ANSYS Theory Reference, Electronic Release 8.0, SAS IP, Inc., Cary, NC, USA, 1998.

[29] ANSYS Inc, ANSYS Element Reference, Electronic Release 8.0, SAS IP, Inc., Cary, NC, USA, 1998.

[30] GB 50017-2003, Code for Design of Steel Structures, Guobiao Standards, Beijing, China, 2003.

[31] H. Y. Ban, G. Shi, Y. J. Shi, and Y. Q. Wang, "Overall buckling behavior of $460 \mathrm{MPa}$ high strength steel columns: 
experimental investigation and design method," Journal of Constructional Steel Research, vol. 74, pp. 140-150, 2012.

[32] Y. Liu and L. B. Hui, "Finite element study of steel single angle beam-columns," Engineering Structures, vol. 32, no. 8, pp. 2087-2095, 2010.

[33] NAS AISI, North American Specifications for the Design of Cold-Formed Steel Structural Members, AISI, Washington, DC, USA, 2007. 


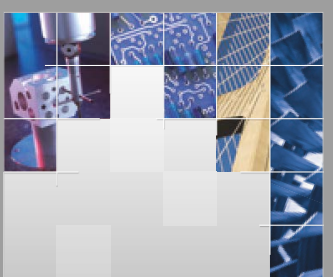

\section{Enfincering}
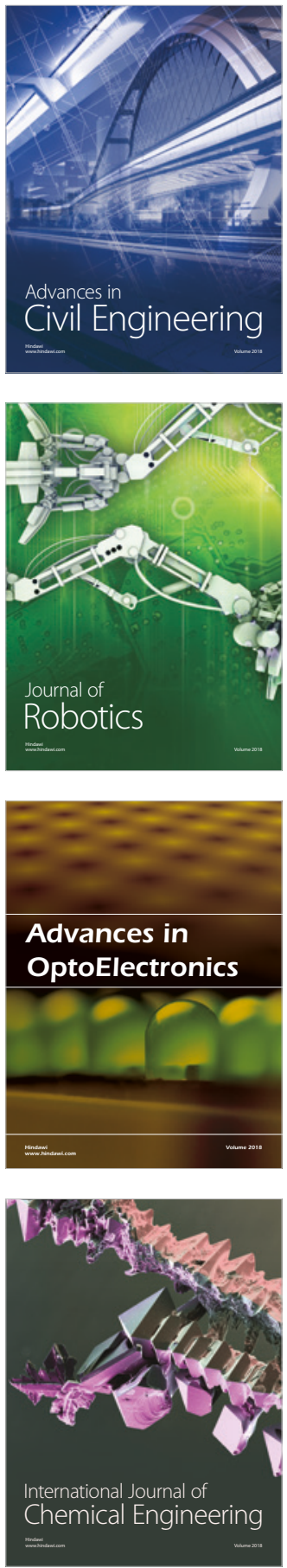

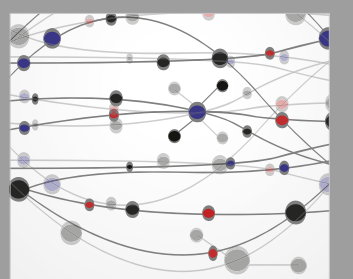

\section{Rotating \\ Machinery}

The Scientific World Journal

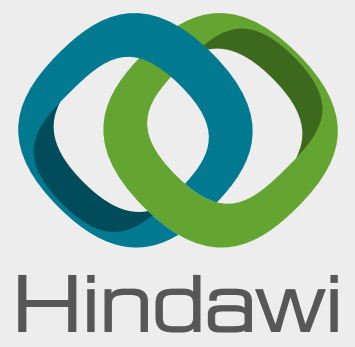

Submit your manuscripts at

www.hindawi.com
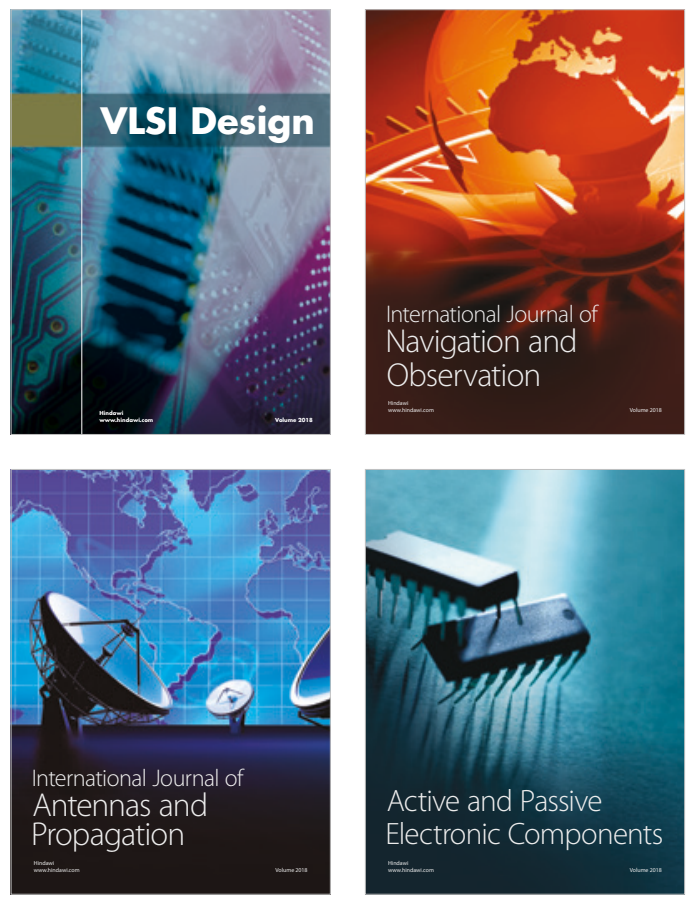
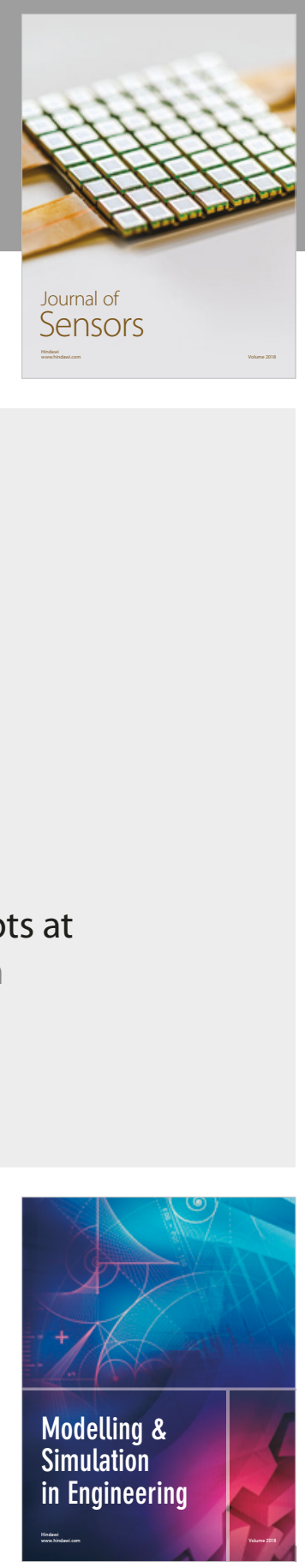

\section{Advances \\ Multimedia}
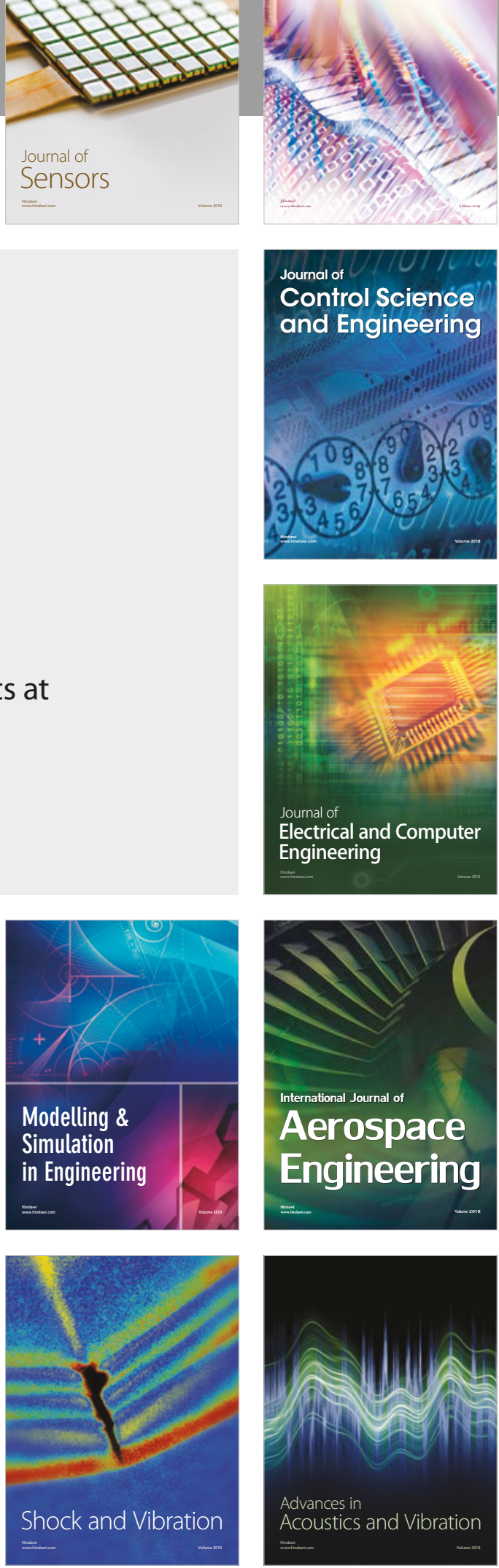